\title{
Active suspension in railway vehicles: a literature survey
}

\author{
Bin Fu $\mathbf{F u}^{1} \cdot$ Rocco Libero Giossi $^{2}(1) \cdot$ Rickard Persson $^{2} \cdot$ Sebastian Stichel $^{2} \cdot$ \\ Stefano Bruni ${ }^{1} \cdot$ Roger Goodall $^{3}$
}

Received: 24 December 2019/Revised: 12 February 2020/Accepted: 13 February 2020/Published online: 9 March 2020

(C) The Author(s) 2020

\begin{abstract}
Since the concept of active suspensions appeared, its large possible benefits has attracted continuous exploration in the field of railway engineering. With new demands of higher speed, better ride comfort and lower maintenance cost for railway vehicles, active suspensions are very promising technologies. Being the starting point of commercial application of active suspensions in rail vehicles, tilting trains have become a great success in some countries. With increased technical maturity of sensors and actuators, active suspension has unprecedented development opportunities. In this work, the basic concepts are summarized with new theories and solutions that have appeared over the last decade. Experimental studies and the implementation status of different active suspension technologies are described as well. Firstly, tilting trains are briefly described. Thereafter, an indepth study for active secondary and primary suspensions is performed. For both topics, after an introductory section an explanation of possible solutions existing in the literature is given. The implementation status is reported. Active secondary suspensions are categorized into active and semi-active suspensions. Primary suspensions are instead divided between acting on solid-axle wheelsets and independently rotating wheels. Lastly, a brief summary and outlook is presented in terms of benefits, research status
\end{abstract}

Rocco Libero Giossi

roccolg@kth.se

1 Dipartimento di Meccanica, Politecnico di Milano, Milan, Italy

2 Division of Rail Vehicles, KTH Royal Institute of Technology, Stockholm, Sweden

3 Institute of Railway Research, University of Huddersfield, Huddersfield, UK and challenges. The potential for active suspensions in railway applications is outlined.

Keywords Active suspension - Railway vehicle · Mechatronics - Control - Active primary suspension · Active secondary suspension

\section{Introduction}

Over the last half-century, railway vehicles have developed in a way that more and more electronics, sensors and controllers are applied along with the traditional mechanical structures to meet the new demands for higher speed, better ride quality and stricter safety requirement. A number of digital technologies in railway engineering have been developed and put in practical use in sub-systems including train management, communication, traction and braking systems. In contrast, only a limited number of active control solutions have been introduced to improve the dynamics of the railway vehicle. Tilting trains, as one of the successful applications, have shown great benefits, which encouraged further explorations of active suspensions over last two decades.

Since the suspension of railway vehicles is a complicated system aimed at achieving different functions, active suspension technologies with different functions and configurations have been developed in various forms. Major reviews were published in 1983, 1997, 2003 and 2007 [1-4]. Many new theories and implementations emerged in the last decade, however. Therefore, in this work, a systematic state-of-the-art review is presented including recent 


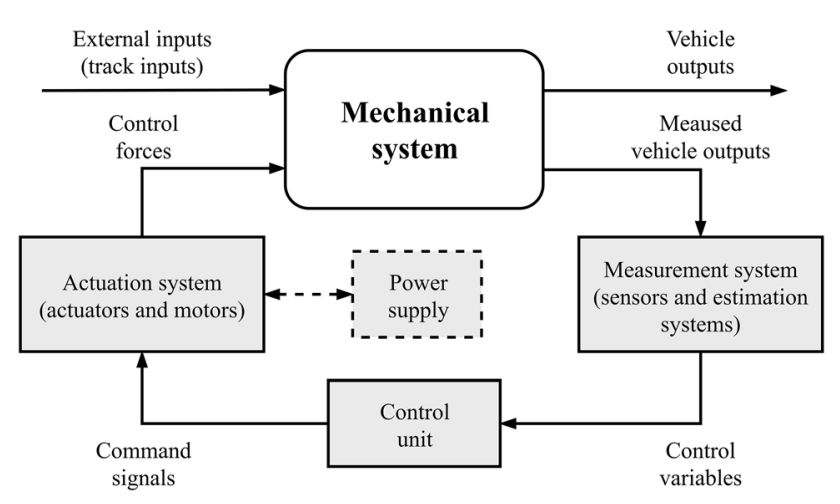

Fig. 1 Workflow of an active suspension

studies on active suspension. In Sect. 2, the general concepts are explained, and a classification of active suspension is introduced. Based on the classification, the different actuation solutions are introduced. Since tilting train can be regarded as a quite mature technology and little development has been made since 2009 [5], it is only briefly introduced in Sect. 3. Emphasis is put on active secondary and primary suspensions that are described in Sects. 4 and 5 , respectively. Finally, Sect. 6 provides a summary and an outlook to future trends and research needs.

\section{Basic concepts of active suspension and classifications}

\subsection{Basic concepts of active suspension}

For a passive suspension, fixed stiffness and damping parameters define the dynamic response of a system. The external excitations of the vehicle suspension system include deterministic (track layout) and stochastic (track irregularity) excitations in different frequency ranges. Therefore, a design of passive suspension with fixed parameters has to find a trade-off solution for different operating conditions. In contrast, a 'global optimum solution' can be achieved by implementing active suspension providing variable suspension parameters features combined utilization of sensors, controllers and actuators. Figure 1 summarizes the generic workflow of an active suspension.

In the workflow, the measurement system will gather the information of vehicles including the accelerations, velocities and displacements directly or indirectly from sensors and filters. Some other information, such as vehicle position and track layout, could be obtained from a georeference system and track database. This information will be analysed in a control unit designed in advance to achieve specific targets. Then, commands will be sent to an actuation system to generate the desired force and finally improve the dynamic performance of railway vehicles.

\subsection{Classifications for active suspension}

\subsubsection{Classification based on suspension location}

There are different approaches to classifying the various active suspension technologies. A natural way is to categorize the technologies into two types according to their location:

a. Active primary suspension.

b. Active secondary suspension.

An active primary suspension is meant to improve the stability, guidance and curve-negotiation behaviour for solid-axle wheelsets (SW) or independently rotating wheels (IRW). An active secondary suspension is aimed at improving the ride quality and controlling the quasi-static motion of car-body, for example with a Hold-Off-Device (HOD). Tilting trains tilt the car-body to a desired rolling angle in curves so that the lateral acceleration perceived by the passengers will be reduced, allowing higher curve-negotiation speed. Tilting trains theoretically belong to active secondary suspension and can integrate other active schemes like HOD, but as a distinctive and well-developed technology, it is reasonable to split it from active secondary suspension as is introduced separately in Sect. 3.

\subsubsection{Classification based on degree of control}

Semi-active and fully active controls are two categories from the perspective of the degree of control. A clear distinction between the two can be seen in Fig. 2. The fully

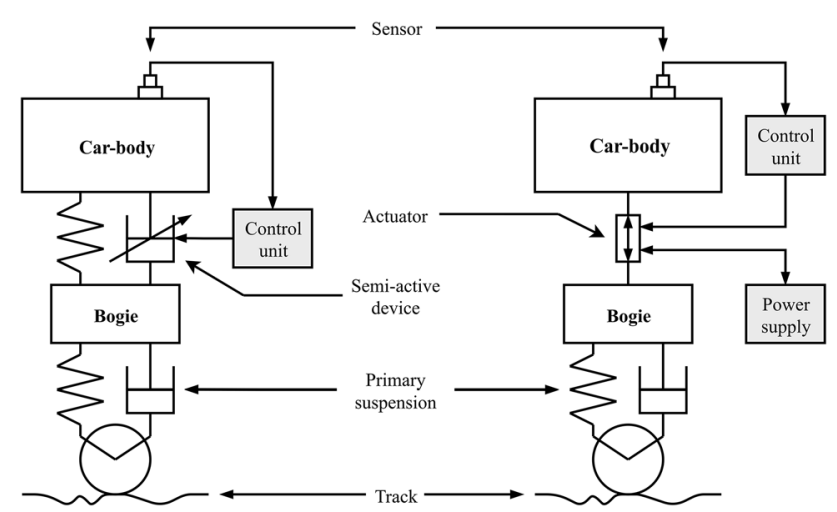

Fig. 2 Schematic diagram for the principles of semi-active (left) and fully active (right) suspensions 


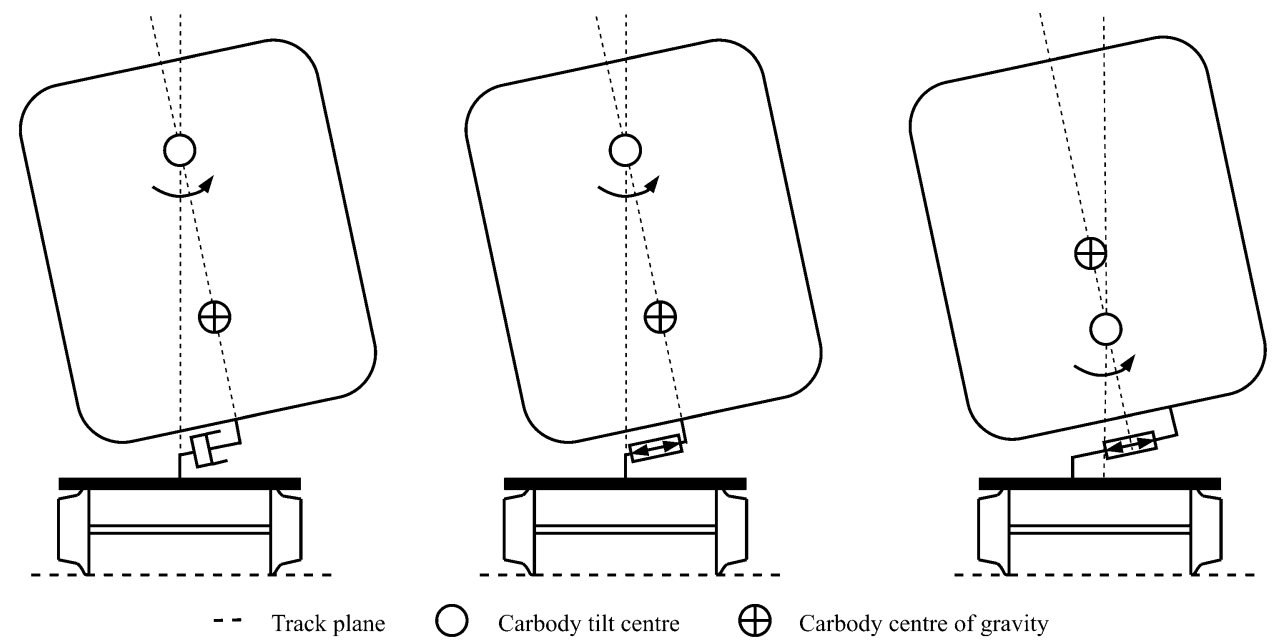

Fig. 3 Natural tilting (left), controlled natural tilting (centre) and active tilting (right)

active control requires a power supply to produce the desired force so that the motion of the mechanical structure can be controlled. In contrast with neither power supply nor actuation system, the controllable variables in semi-active suspension are those parameters of passive suspension: adjustable stiffness spring [6], adjustable inerter [7] and adjustable damper [8]. Most studies focus on the last one. In semi-active suspension, as the damping force generated is still dependent upon the speed of the damper, the improvement of vehicle dynamics is naturally constrained. For instance, semi-active control cannot create the desired force for low-frequency vibrations or in quasi-static conditions. However, the simplicity of semi-active damper makes it easier to implement so it can serve as a trade-off solution between passive suspension and fully active suspension.

\subsubsection{Classification based on functions}

Another kind of classification for active suspension is based on the purpose of the active control [1]. Four types are categorized as follows:

a. Isolating the vehicle body from track irregularities (i.e. ride comfort).

b. Controlling kinematic modes of the bogie (i.e. stability).

c. Steering and guidance of the wheelsets (i.e. active steering).

d. Special functions in addition to passive suspensions (i.e. tilting trains, HOD).

Since the purpose of active suspension decides control targets and the interesting frequency range, the active control schemes consisting of controllers, sensors and actuators will vary accordingly. Therefore, this classification helps the organization of the description of control strategies and other parts. In this state-of-the-art review work, the idea of this classification is applied within each subsection. For instance, when it comes to the active primary suspension system, the control strategies are introduced based on the functions of 'steering' and 'stability' separately.

\section{Tilting trains}

Car-body tilting is a well-established technology in railway vehicles. Its aim is to reduce the lateral acceleration perceived by the passengers by rolling the car-body inwards during curve negotiation. This solution leads to an increased comfort that eventually permits a higher speed during curves negotiation reducing the overall traveling time. As reported by Persson et al. [5], the running time benefit can be up to $10 \%$ for a tilting train with respect to a non-tilting one with the same top speed.

A first attempt of tilting mechanism was introduced in the late 1930s [9] while the first operating tilting coach was developed in 1938 by Atchison, Topeka and Santa Fe Railway [10]. In the 1980s, natural tilting trains were introduced in Spain with the Talgo Pendular trains [11]. The first mass production of actively tilting trains was introduced in Canada with the LRC in 1981 followed by Italy with the ETR450 and in Sweden with the X2000 in the 1990s, while the first high-speed train was introduced in Japan in 2007 with the Shinkansen Series N700 [5, 12].

According to titling principles, tilting trains can be divided into (1) natural and (2) active tilting. In natural tilting, the roll of the car-body is obtained thanks to the centrifugal force acting on the car-body itself. The natural tilting is possible only if the car-body centre of gravity is 

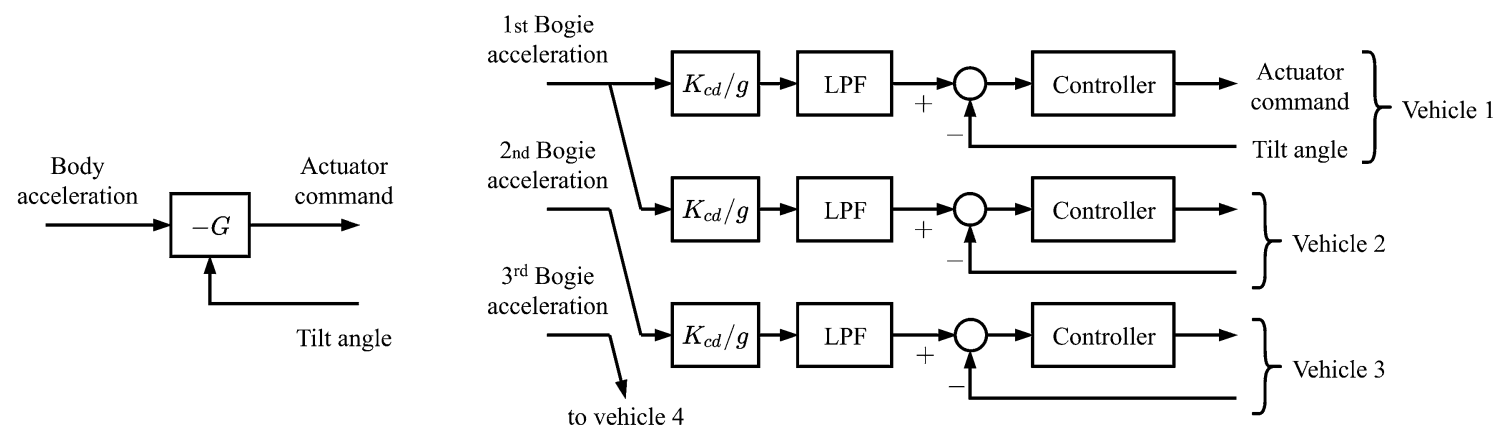

Fig. 4 Tilting controls: nulling control (left), precedence control (right)

placed below the tilt centre. In Fig. 3 left, a representation of this mechanism is shown.

One commercial success of the natural tilting is the Talgo trains [13], in which the natural tilting is achieved by placing the air springs in a high position, thus shifting the tilting centre. Natural tilting is a fail-safe and low-cost mechanical system [5], but it will shift the position of the car-body centre of gravity laterally and thereby increasing the risk of overturning. Moreover, the car-body moment of inertia will delay the tilt motion in transition curves increasing the risk of motion sickness in sensitive passengers. For these reasons, often a controlled natural tilting is applied (Fig. 3 centre). Here, an actuator is introduced to reduce lateral acceleration fluctuation in transition curves. Additionally, it is used to initiate the tilt motion before the curve negotiation to reduce the delay in the tilt motion and decrease the risk of motion sickness. For the active tilt (Fig. 3 right), the centre of gravity does not have to be lower than the tilt centre because the motion is provided by dedicated actuation, but it is often arranged to return the car-body to an upright position in case of failure. As reported by Persson et al. [5], tilting control evolved from the so-called nulling controller to the precedence control strategy. These control strategies are shown in Fig. 4.

In the nulling controller, the lateral acceleration of the car-body is measured through the usage of an accelerometer and a negative feedback to tilt the car-body to bring the car-body lateral acceleration close to zero. This approach finds difficulties due to that the secondary suspension, with its low frequencies, is inside the control loop. To solve the problem, the acceleration measurement is moved outside the control loop, to the non-tilting part of the bogie. The control loop without the secondary suspension could now be designed with high gain and good controllability. The acceleration measurement in the bogie is creating a reference to the control loop. A low-pass filter must be added in this case to attenuate the acceleration contribution due to track irregularities. The low-pass filter causes delay in transition curves, which leads to introduction of precedence control. In this approach, the reference is generated by the vehicle in front to command the subsequent vehicle. The filtering delay is in this case carefully designed to fit the precedence time corresponding to a vehicle length. Despite the fact that precedence control is now one of the most used strategies in European tilting trains, research is continuing to improve the performance by studying the possibility of track knowledge control or improving the control on the actuation systems or to remove precedence control by applying local vehicle measurements alone.

In the field of local vehicle measurements, Zamzuri et al. [14] showed a promising utilization of a proportional-integral-derivative (PID) nulling-type control with fuzzy correction scheme. In the study, the proposed controller was compared with a fuzzy extension of a conventional PI controller showing improved performances. Concerning the nulling-type control, Hassan et al. [15, 16] used optimization procedures to enhance the performances of the PID approach maintaining required robustness of the controller. Subsequently, Zhou et al. [17] proposed a combination of tilt and active lateral secondary suspension control. A decentralization method was used to control separately tilting and lateral dynamics based on measurements of lateral acceleration, actuator roll and suspension deflection. Nevertheless, as previously mentioned, feedback signals measured on the vehicle can introduce issues in the control application. To counteract this problem, Zhou et al. [18] introduced a robust state estimation based on $H_{\infty}$ filtering to estimate the vehicle body lateral acceleration and true cant deficiency. The $H_{\infty}$ filtering was then compared with a standard Kalman filter showing good results.

Facchinetti et al. [19, 20], using a similar approach of Zhou in [17] of a combination of tilting and active lateral control, studied the possibility of using active air springs and pneumatic secondary suspension. A combination of feedforward and feedback actions was introduced, and its effectiveness was tested on a full-scale test stand consisting of one bogie and a ballast mass reproducing the inertia of a half car-body. A similar approach in terms of feedforward and feedback combination was used by Colombo et al. [21] 




Fig. 5 Mutual relationship between ride comfort, vehicle speed and track quality

to control interconnected hydraulic actuators. The purpose of interconnected hydraulic actuators was to actuate the car-body tilting and provide the same car-body to bogie stiffness as a conventional anti-roll bar. Three different control approaches were tested showing that a combination of feedforward, PID and sky-hook controls could provide the best performance in terms of ride comfort for an acceptable actuation power requirement. An alternative approach was studied by Jacazio et al. [22]. An adaptive PID control was developed with the objective of minimizing the hydraulic actuators' power losses while maintaining the required dynamic performances. The adaptation was based on the outside temperature and the force to be developed by the actuators. Simulation results based on real track data showed saving of $10 \%-20 \%$ of the electric power required by train auxiliary systems. Although hydraulic actuators were described in some references above, electro-mechanical actuators have been used in many new European tilting trains today because of their high efficiency [5].

An enhancement in tilting control is the utilization of stored track data to predict the upcoming curve and reduce the delay in the actuation system [23]. Here, lateral acceleration and roll and yaw signals are combined with the track data to compute the command angle to be provided by the actuator. Another usage of stored track data was given by Persson et al. [24]. Here, a new tilting algorithm was used for on-track tests to reduce motion sickness. The algorithm was fed with the stored track data and the position of the vehicle on the track provided by a positioning system to select the appropriate data. The approach was tested on 100 subjects giving promising results both on comfort improvements and motion sickness reduction.

\section{Active secondary suspension}

\subsection{Principles and configurations}

The secondary suspension in railway vehicles is aiming to attenuate vehicle vibrations from track irregularities while transferring static and quasi-static loads from the car-body to bogie with constrained deflections.

However, the aim of good vibrational attenuation is contradictory to small deflections, limiting the performance of a passive secondary suspension. Active secondary suspension can be designed to meet both aims at the same time. Three applicable concepts concerning ride comfort, vehicle speed and track quality are summarized below according to their mutual relationship shown in Fig. 5 .

a. Improve passenger ride comfort at current speed and track condition;

b. Enable enhanced speed at maintained ride comfort and no higher demand on track quality;

c. Allow lower track quality without compromising ride comfort and speed.

The ride quality of most railway vehicles with passive suspension is already satisfactory today, which means that the first applicable concept is not so attractive while the other two still make its implementation worthwhile.

For the configuration of the active secondary suspension, actuators are generally placed between the bogie and the car-body in lateral or vertical direction. The passive air springs can also be modified as actuators to control the vibration in the low-frequency range [20].

Active secondary suspension can be introduced in different mechanical configurations in relation to the passive springs, as shown in Fig. 6. Actuators can directly replace the original passive springs from bogie to car-body and independently control the motion of the vehicle. However, considering the dynamic characteristics of different actuators, it is more practical to implement actuators in addition to passive springs in parallel or in series to complement the actuators. When paralleled with actuators, passive springs can carry the static and quasi-static load in vertical and lateral direction which in turn reduces the requirement for actuators and thereby enables small dimensions of actuators. When connected in series with actuators, the passive springs can isolate the high-frequency excitations that actuation system cannot react because of its potential ineffectiveness in high-frequency range. In practical applications, combinations of both series and parallel springs can be used.

A special configuration for active secondary suspension proposed by Mei et al. [25] is implementing actuators between the adjacent car-bodies in a train set, which is illustrated in Fig. 7. In this configuration, the number of actuators can be reduced. The working environment is friendly to sensors and actuators since vibrations have been attenuated by the passive suspensions. This leads to higher reliability of the actuation system. Zhou applied a similar configuration in lateral direction [26]. 

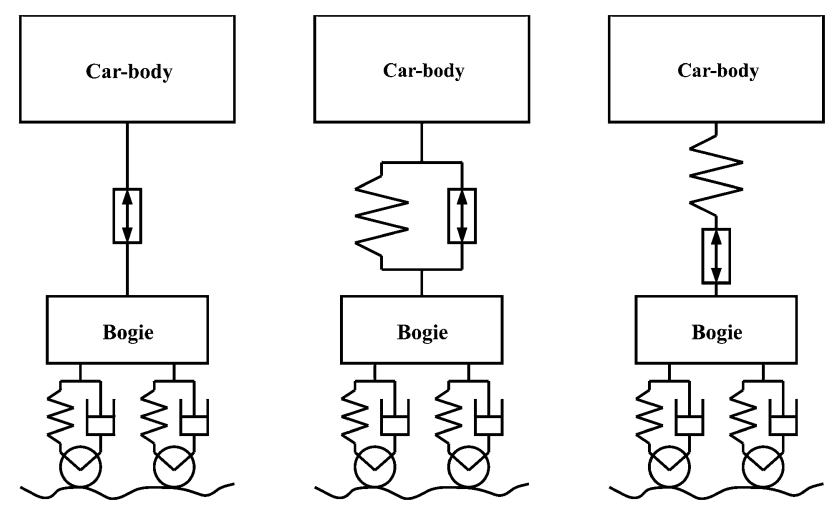

Fig. 6 Mechanical configurations of active secondary suspension

Disregarding longitudinal train dynamics, the remaining five rigid car-body motions (lateral, vertical and the three rotations) can be controlled by a combination of vertical and lateral active suspensions. Lateral motion and yaw motion alone or together can be controlled by active lateral suspension, while the active vertical suspension is meant to attenuate bouncing and pitching vibrations. Rolling control can be realized by either lateral or vertical active control, which is the main goal for tilting trains. It is common to consider different motions in an integrated control scheme which is also known as modal separation control. This will be introduced in detail in Sect. 4.2.1.

Active systems aimed at improving ride comfort are typically installed in the secondary suspension, but there are examples where active control in primary suspension is proposed to attenuate the vibration of the car-body. A recent work shows that semi-active vertical primary suspension has potential to reduce car-body first bendingmode vibration [27]. Although this belongs to active primary suspension technically, the control strategy and implementation status are described in Sects. 4.2.13 and 4.3.3, respectively, as the ultimate scope of this application is to improve ride comfort.

\subsection{Active secondary suspension control strategies}

\subsubsection{Fully active control in high bandwidth}

High-bandwidth control deals with stochastic vibration excited from track irregularities to improve passenger ride comfort. Before the introduction to the control strategies, it is worth mentioning different methods to evaluate the ride comfort. The method prescribed in EN 12299 [28], or the Ride Index $W_{Z}$ [29] is usually used which takes into consideration the RMS value of frequency-weighted accelerations on the car-body floor. The weighting functions are used to reflect the human interpretation of ride comfort. The human body is most sensitive in the range between 0.5 and $10 \mathrm{~Hz}$. The weighting functions vary depending on methods and directions.

Rigid car-body modes are generally in a frequency range around $1 \mathrm{~Hz}$ while modes involving car-body deformability relevant to ride comfort fall between 8 and $15 \mathrm{~Hz}$ [30]. Bogie rigid modes are often in the range of 5 to $10 \mathrm{~Hz}$. Thus, it is important to properly design the secondary suspension system to avoid unacceptable levels of ride quality due to poor separation between different resonance frequencies. Moreover, the general demand of higher speeds in rail vehicles requires lighter car-bodies resulting in lower structural stiffness, which eventually results in lower natural frequencies. This effect tends to worsen ride comfort. Once a passive system is optimized, a good way to improve passenger comfort is the usage of an active (or semi-active) suspension system to suppress undesired vibrations coming from the track.

In the literature, different control approaches are used like Modal control, LQG and $H_{\infty}$, but these concepts may not be adopted independently. Therefore, in Fig. 8 their relationship is organized in substructures. Other concepts exist but they are not considered here. One main distinction can be found between model-based and non-model-based controllers. Model-based controls including $H_{\infty}$ and LQG can produce better performances but at the same time they can suffer from unmodeled behaviours and parameter



Fig. 7 Configuration for inter-vehicle actuation system [25] 




Fig. 8 Control approaches

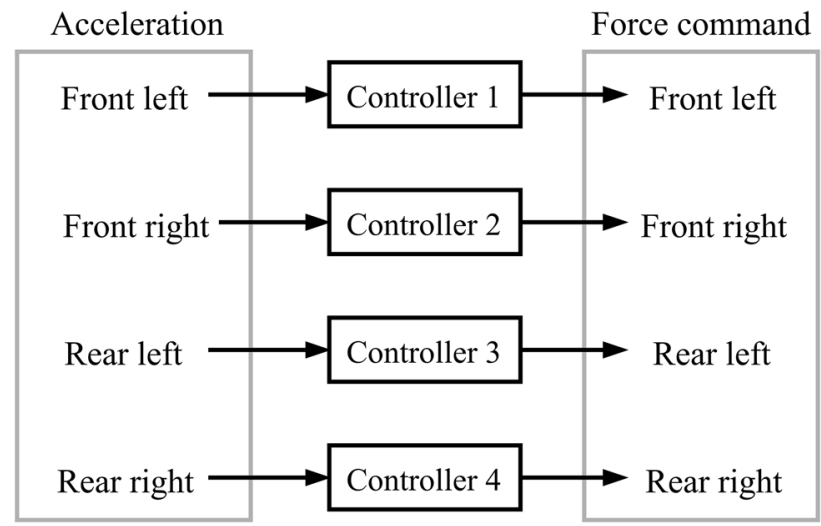

Fig. 9 Example of local control

uncertainties. The dashed line in Fig. 8 indicates that a model-based approach may be used but it is not necessary to design a sky-hook or fuzzy controller. The second distinction can be found in the application of a modal separation approach. This approach goes by the name of modal control and will be explained next. In the following, six categories are introduced and their applications in fully active control in high bandwidth are shown. The control concepts are as follows: (a) modal control (b) sky-hook damping control, (c) linear quadratic Gaussian (LQG) control, (d) $H_{\infty}$ control and (e) fuzzy control. A separate mention will be given to (f) inter-vehicle actuator control.

\section{(a) Modal control}

To help the understanding of the concept of modal control, the so-called local control, shown in Fig. 9, is introduced first. In this approach, the global system is not directly considered. Benefits on the system come from separate localized actions. In this approach, each sensor-controlleractuator triplet creates a separate subsystem that has no direct communications with the others.

In contrast, the target of modal control is to attenuate different motions efficiently using one common control strategy. The modal decomposition is achieved by processing the acceleration measured at different locations in the car-body. Then, to suppress each single mode, the desired actuation forces will be calculated separately, and these forces will be superimposed so that finally the different vibration modes can be damped at the same time. An example of modal control is given in Fig. 10 in which the modal separation is applied to bounce, pitch and roll motions of the car-body.

Orvnäs applied this idea to design control schemes for lateral, yaw and roll motions control [31] as well as for bounce, pitch and roll motions control [32]. The control scheme proposed and applied in [31] is shown in Fig. 11. In this scheme, sensors mounted on front and rear position of the car-body will measure lateral accelerations. Then, the sum and difference of the two signals are processed to reflect the lateral oscillation and yaw motion separately. Then, forces aimed at controlling the motions will be generated according to sky-hook or $H_{\infty}$ control. Moreover, the lateral acceleration of the bogie is low-pass filtered and half the bogie mass is used as gain to form the force reference for HOD function. The idea of modal control is also applied in the studies by Hammood and Mei [33], Sugahara et al. [34], Yusof et al. [35], and Qazizadeh et al. [36, 37].

\section{(b) Sky-hook damping control}

Sky-hook damping control, also known as absolute damping, was introduced by Karnopp [38], and is one of the simplest and most effective control techniques for vibration isolation. The basic idea on sky-hook control relies on the concept shown in Fig. 12 centre. To solve the trade-off problem of passive suspensions between resonance frequency amplitude attenuation and higher frequencies amplitude magnification, the damper is moved from the original position of Fig. 12 left to be connected to a virtual constraint called 'sky'. In practice, the damper still has to be mounted between the car-body and the bogie. Thus, a control force is introduced to produce the same effect of the desired 'sky' configuration. This concept is illustrated in Fig. 12 right.

Ideally, the sky-hook force applied on the car-body can be calculated according to Eq. (1).

$F_{\text {sky }}=-C_{p} \dot{x}_{2}$

where $F_{\text {sky }}$ is the desired force acting on car-body, $C_{p}$ is controllable damping and $\dot{x}_{2}$ is the velocity of the car-body in the lateral or vertical direction.

The ride quality on tangent track can be significantly improved by applying a sky-hook damper, but the deflection of the suspension is enlarged on deterministic track segments like curves and gradients. In a real implementation, the car-body and bogie velocities are produced by integration of acceleration. Consequently, the integration of quasi-static acceleration as the lateral acceleration in curves must be avoided. The velocities are therefore highpass filtered after the integration. This solution will also 




Fig. 10 Example of modal control scheme

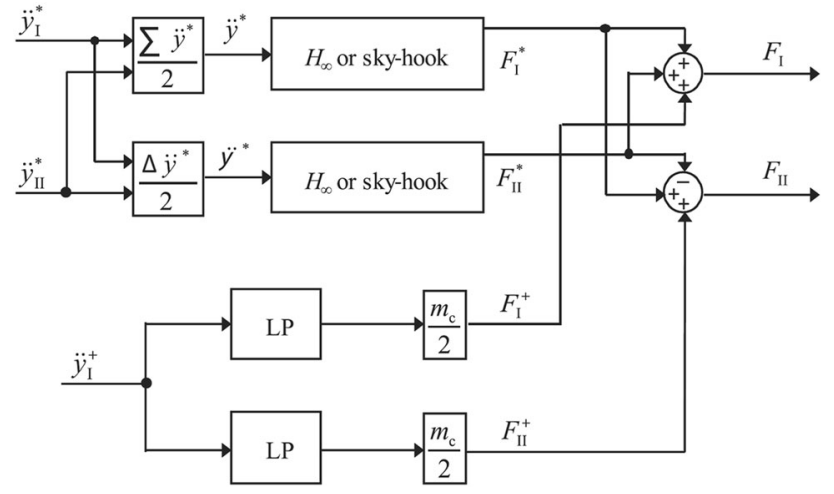

Fig. 11 Modal control considering lateral and yaw motion in conjunction with HOD [31]

mitigate any thermal drift in the sensors. Figure 13 gives the workflow for sky-hook damping.

Thanks to the simplicity of sky-hook control, it is the one that finds application in full-size vehicle tests (Qazizadeh et al. [36, 37] and Sugahara et al. [39, 40]). In scientific studies, the sky-hook control is also used as reference to prove the effectiveness of other refined control techniques by Gopala Rao et al. [41], Sugahara et al. [39], [40], Pacchioni et al. [42] and Orukpe et al. [43].

The damping factor (gain) for sky-hook control can be set as critical damping, but this is not necessarily the best choice. Efforts are made to improve the performances of sky-hook control and a few examples are given here. Linear and nonlinear approaches were explored with different filtering techniques to improve ride comfort and minimize suspension deflection [44]. Turnip et al. [45] introduced a sensitivity approach to improve sky-hook performances at high frequencies. Hammood and Mei [33] used a gain-scheduling approach based on the difference between car-body and bogie speeds to improve the performances while Yusof et al. [35] used non-dominated sort genetic algorithm II (NSGA II) to optimize control gain and actuator stiffness. With a careful choice of the control parameters, sky-hook performances can match the performances of a linear quadratic regulator (LQR) [41].
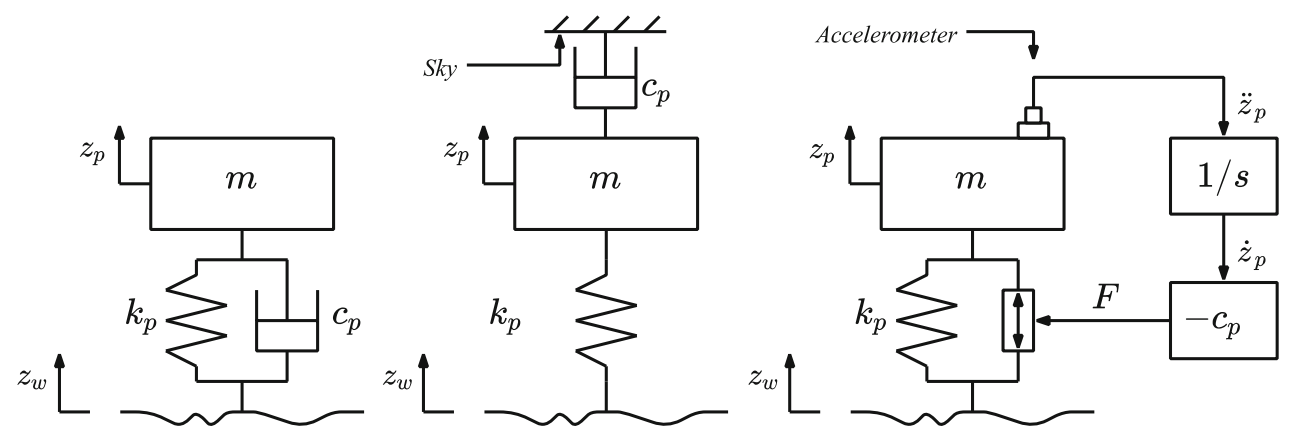

Fig. 12 One-DOF problem: passive system (left), ideal sky-hook (centre), and sky-hook damping control (right) 


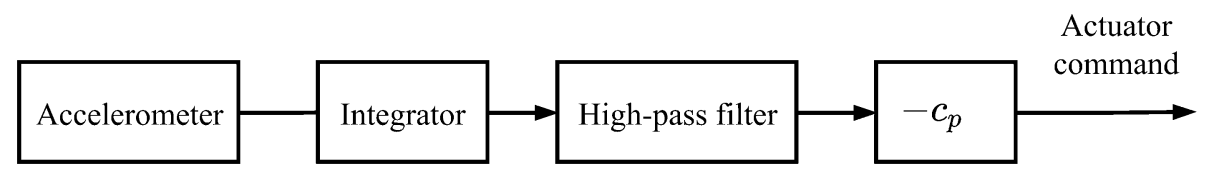

Fig. 13 The workflow for sky-hook damper

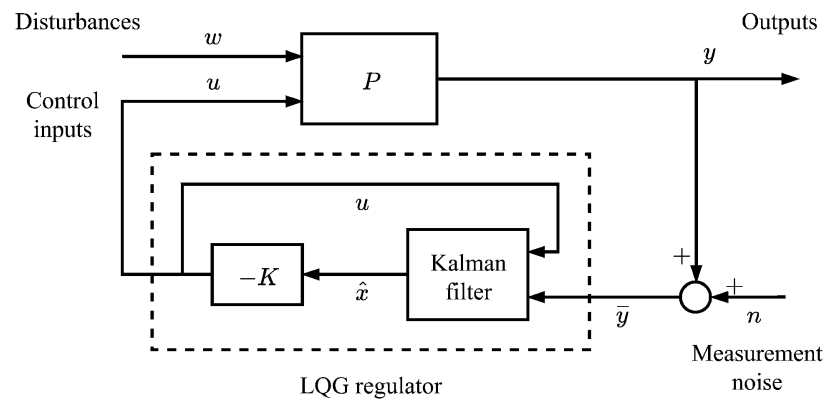

Fig. 14 LQG control scheme



Fig. $15 H_{\infty}$ control scheme

\section{(c) Linear quadratic Gaussian (LQG) control}

LQG control is a combination of $\mathrm{LQR}$ and a Kalman filter to create a model-based control. The LQG controller is aimed at optimizing the performances based on specific penalty values assigned to the state vector $x$ and the input vector $u$. It must be mentioned that in many implementations, the Kalman-Bucy filter or its digital equivalent is used rather than the more general form of Kalman filter. A graphical representation of this control is given in Fig. 14.

A successful implementation of LQG was described by Gong et al. [46], where it was combined with preview control. It is shown that LQG control is effective in control of both rigid and elastic modes together over a wide frequency range. An interesting application was studied by Leblebici and Türkay [47]. Here, a lumped track model was introduced, and it was proven through simulations that the LQG control can effectively counteract bounce and pitch motions of the car-body. A quarter car model with nonlinear suspensions was studied by Nagarkar et al. [48] where NSGA II was used to optimize PID and LQR control parameters with a multiple objective problem compromising ride comfort, suspension space and control force. Sugahara et al. [40] compared sky-hook damping and LQG control both by simulation and test on a full-scale model. It is shown that LQG control works better when the natural frequency of the first bending mode of the car-body is far from the bogie one while the sky-hook damping improves the response when these two are close to each other. A similar approach was applied by Pacchioni et al. [42]. Here, it is shown that with a careful choice of the gains similar effects can be produced by sky-hook and LQG. Nevertheless, as discussed by Sugahara et al. [39], LQG control can be a precise control but it can suffer from unmodeled uncertainty or even dynamics that can cause a drastic decrease in the controller performances.

(d) $H_{\infty}$ control

$H_{\infty}$ control is a robust model-based control technique using measurement feedback to produce a stable controller that handles unmodeled dynamics of the plant and model uncertainties. A graphical representation of this control is given in Fig. 15.

$H_{\infty}$ was introduced into control theory in the late 1970s. One of the first applications of $H_{\infty}$ control to the control of vehicle modes was carried out by Hirata et al. [49, 50] where lateral roll and yaw motions were successfully attenuated in the low-frequency region. This type of control was extensively used by Kamada et al. [51-53]. Here, the effectiveness of the control strategy is shown both with simulations and experimental tests on a 1:6 scale model of Shinkansen vehicle. The usage of the $H_{\infty}$ control is especially useful for piezoelectric actuators. The robust $H_{\infty}$ control overcomes the problem of unmodeled behaviours and uncertainty on parameters of the piezoelectric actuators [51]. A $H_{\infty}$-sky-hook control was developed by Leblebici and Türkay [54] showing the possibility of achieving good amplitude reduction near the resonance frequencies of the car-body. The development of a $H_{\infty}$-sky-hook control is possible due to the measurement feedback approach. A comparison in performance evaluation was carried out between sky-hook control and model predictive control (MPC) based on mixed $H_{2} / H_{\infty}$ using linear matrix inequality (LMI) by Orukpe et al. [43]. It is shown through simulations that MPC better suppresses the bounce motion 


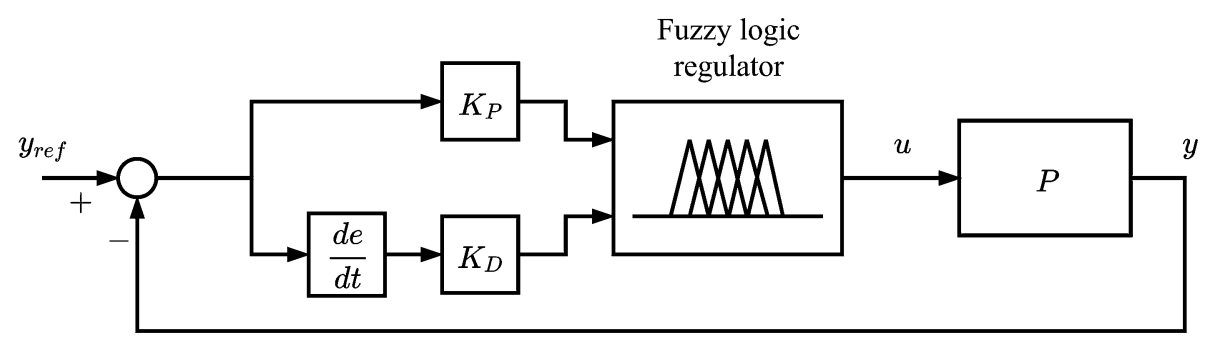

Fig. 16 PD fuzzy control scheme example

of the vehicle than the classical sky-hook control while keeping the suspension deflection within a similar range and producing comparable forces.

\section{(e) Fuzzy control}

Fuzzy logics come from the definition of fuzzy sets which was first introduced by Zadeh [55] in 1965. By definition, a fuzzy set is a set to which a variable may belong partially. This gives the possibility to the fuzzy logic to decide accordingly to a defined linguistic rule which output (control input) to choose depending on the combination of the inputs it takes (error between reference signal and system output or measurements). A graphic representation of a fuzzy logic implementation is given in Fig. 16.

Fuzzy logic control was successfully applied by Guclu and Metin [56] on a tram with a three-bogie configuration. Good results were presented in time and frequency domain with simulation results. In a subsequent work Metin and Guclu [57] compared the results obtained with a PID control with fuzzy logic control. Both controls are tuned with the use of genetic algorithms (GAs). It is shown by simulations that the fuzzy one improves the performances. A self-tuning fuzzy logic approach was implemented by Sezer and Atalay [58] achieving good results in terms of acceleration reduction and proving the robustness of the implemented approach against car-body mass variation.
The simulation results were shown in terms of time and frequency domain analysis showing that low-frequency amplitude was properly attenuated.

(f) Inter-vehicle actuator control

Since the inter-vehicle actuation system has a special arrangement as shown in Fig. 7, the proposed control strategy is unique. When actuators connect the adjacent car-bodies, the motions of the car-bodies are coupled so that the whole train set should be considered as a complete system. As each car-body is equally important, control objectives are multiplied with increasing number of interconnected car-bodies. The complexity of the system makes model-based control strategies too complicated to implement, while multi-objective GAs are introduced and turn out to be effective [25]. In this work, a three-car-body train set is studied, where the objective function $\mathbf{J}$ is created considering RMS values of acceleration measured from the front, middle and rear positions for each car-body.

Each desired actuator force is optimized through GAs to minimize the objective function. Constraint function could also be introduced to limit the deflection of suspension in low bandwidth. In this way, the knowledge of the vehicle dynamic model is not required. Instead, the control is purely based on an optimal mathematic model. This control

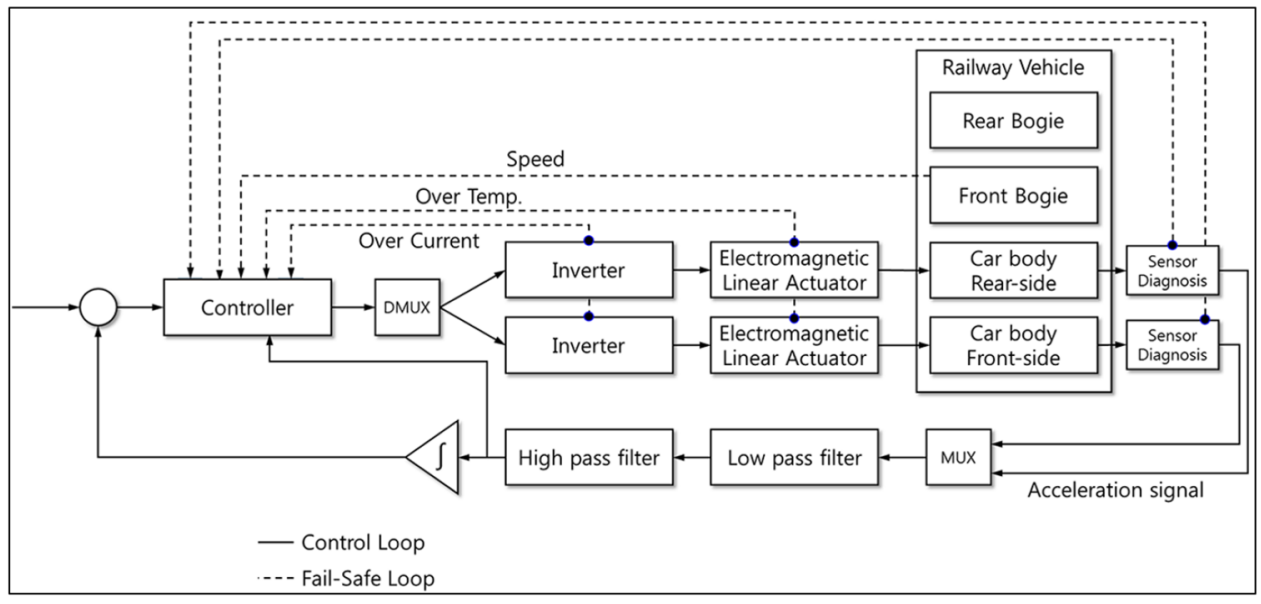

Fig. 17 Fail-safe control scheme for active lateral suspension system [75] 


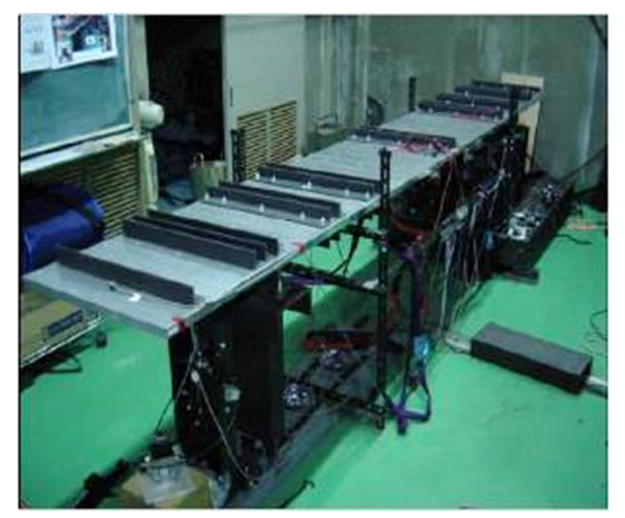

Fig. 18 Experimental set-up [51-53]



Fig. 19 Actuator replacement in Regina $250[36,37]$

idea can be applied for other multi-objective control targets, as is shown in Eq. (2) [59].

$J=\int\left(q_{1} a_{\mathrm{b}}^{2}+q_{2} x_{\mathrm{d}}^{2}+r F_{\mathrm{a}}^{2}\right) \mathrm{d} t$,

where $a_{\mathrm{b}}, x_{\mathrm{d}}$ and $F_{\mathrm{a}}$ are body acceleration, suspension deflection and actuator force, respectively, and the coefficients in front of each index are their weighting factors. So, through the definition of objective function $J$, different control targets can be considered in one scheme.

\subsubsection{Fully active control in low bandwidth (hold-off- device)}

Hold-off-device, as a typical application of active control in low bandwidth, was first proposed by Allen [60]. The target of this application is to generate a force in the lateral direction to counteract the movement of the car-body with respect to the bogie in curves so that the car-body will hold off the stiff bump stop. Consequently, the ride comfort will be improved, and bump stop clearance can be reduced to increase the width of the car-body. Alternatively, with the suspension deflection unchanged, the HOD allows for softer lateral secondary springs which means a better ride comfort can be achieved. Besides, the instability and risk of overturning in strong crosswind can be reduced since the car-body centre of mass position displacement will be restricted by the reduced bump stop gap.

For the control strategy, the low-pass filters are used to process the lateral acceleration of bogie or car-body so that the track layout information will be extracted. Orvnäs calculated the reference actuation force for centring the car-body as product of car-body mass and bogie lateral acceleration [31]. A recent work considered the allowed small deflection of secondary suspension [61]. When lateral displacement exceeds the limit value $d_{1}$, the HOD will be activated and provide the actuation force according to Eq. (3) [62].

$F_{\text {act }}=M_{\mathrm{c}} a_{\mathrm{c}}-K_{1} d_{1}$,

where $M_{\mathrm{c}} a_{\mathrm{c}}$ is the product of car-body mass and lateral acceleration; $K_{1}$ represents the sum of lateral stiffness in secondary passive suspension.

\subsubsection{Semi-active control}

For the control of semi-active suspension, the above-introduced full-active control strategies can be referred. The idea of modal separation, sky-hook control, $H_{\infty}$ control, LQG control, etc., can also be applied in a semi-active suspension. In the design of control schemes, the features of a variable damper must be considered. They can be divided into two types according to the degree of control: two-state/on-off variable damper and continuously variable damper. The former damper works either with maximum or minimum damping rate. The control strategy for this simple damper is decision-making between the two states, which can be achieved by high-level and low-level voltage or current signals. In contrast, the continuously variable damper requires a more complicated control, but it has the potential to provide better performance. Sky-hook control is used here as example to further illustrate their features.

Two-state sky-hook control is the most frequently used control strategy. The high damping state $C_{\max }$ and low damping state $C_{\min }$ are determined by the sign of directions of car-body velocities $\left(\dot{x}_{2}\right)$ and relative velocity between car-body and bogie $\left(\dot{x}_{2}-\dot{x}_{1}\right)$,

$C_{p}=\left\{\begin{array}{ll}C_{\max } & \dot{x}_{2}\left(\dot{x}_{2}-\dot{x}_{1}\right) \geq 0 \\ C_{\min } & \dot{x}_{2}\left(\dot{x}_{2}-\dot{x}_{1}\right)<0\end{array}\right.$.

However, Eq. (5) shows a damping force applied on the car-body which does not fit the definition of sky-hook 




Fig. 20 Roller rig test in 1:5 scale [86]

control in Eq. (1), since the dampers connect bogie and car-body and therefore the bogie velocity is involved.

$F_{\text {sky }}=\left\{\begin{array}{ll}-C_{\max }\left(\dot{x}_{2}-\dot{x}_{1}\right) & \dot{x}_{2}\left(\dot{x}_{2}-\dot{x}_{1}\right) \geq 0 \\ -C_{\min }\left(\dot{x}_{2}-\dot{x}_{1}\right) & \dot{x}_{2}\left(\dot{x}_{2}-\dot{x}_{1}\right)<0\end{array}\right.$.

This problem can be solved by implementing continuous sky-hook control shown in Eq. (6), where not only the sign but also the magnitude of the bogie and car-body velocities decides the reference damping.

$C_{p}^{\prime}=\left\{\begin{array}{ll}\min \left[C_{\max } \frac{\dot{x}_{2}}{\left(\dot{x}_{2}-\dot{x}_{1}\right)}, C_{\max }\right] & \dot{x}_{2}\left(\dot{x}_{2}-\dot{x}_{1}\right) \geq 0 \\ \max \left[C_{\min } \frac{\dot{x}_{2}}{\left(\dot{x}_{2}-\dot{x}_{1}\right)}, C_{\min }\right] & \dot{x}_{2}\left(\dot{x}_{2}-\dot{x}_{1}\right)<0\end{array}\right.$.

This control law can produce the ideal sky-hook damping force, but it means a higher demand for adjustable damping technology and an additional controller for the damper to generate the desired force. For instance, a magneto-rheological (MR) damper is a promising technology, but it has strong nonlinear dynamic behaviour. The input current or voltage is not proportional to the damping force generated. Therefore, in order to obtain the reference damping force, the command signals for the damper need to be pre-calculated [62].

Sky-hook control for semi-active suspension has relatively poor performance in the high-frequency range, so various improvements of this classic control law have been proposed. Savaresi introduced acceleration-driven-damper (ADD) where the acceleration of the car-body was used to calculate the reference damping [63]. The results validate the improved attenuating effect in high-frequency vibration but also confirm the poor performance of this control scheme in the low-frequency range. Therefore, a mixed sky-hook and ADD control strategy was proposed to take advantages of the two controls and provide good results over a wider frequency range [64].

A bogie-based sky-hook control was compared with the classic car-body-based sky-hook by Hudha [65]. The simulation results of a 17 DOF dynamic model show that the bogie-based control can better attenuate the vibration in terms of lateral, roll and yaw motions.

Advanced controls are investigated through simulation to achieve more complicated control targets. A LQG control law was applied by Wang $[66,67]$ where a MR damper was applied to reduce the vibration in lateral, yaw and roll directions. Three working modes of semi-active control (passive-off, passive on and semi-active) were compared. Zong investigated $H_{\infty}$ and the use of adaptive neuro-fuzzy interference system (ANFIS) for the control of MR damper. The lateral, yaw and roll acceleration can be reduced by $30 \%$ according to the simulation results [62].

A control strategy for an adjustable damper in primary vertical suspension was explored for suppressing highfrequent first bending mode of the car-body vibration $[39,68]$. Through the idea of modal separation, both bounce and pitch motions of the bogie are controlled according to the sky-hook control. Although any measurement of car-body vibration is not required in this



Fig. 21 Roller stock test plant [68] (left) and installation of semi-active primary vertical damper [40] (right) 
Table 1 Six concepts of active primary suspensions

\begin{tabular}{|c|c|}
\hline Wheelset types & $\begin{array}{l}\text { Configurations of active primary } \\
\text { suspension }\end{array}$ \\
\hline Solid-axle wheelsets & $\begin{array}{l}\text { Actuated solid-axle wheelset (ASW) } \\
\text { Secondary yaw control (SYC) } \\
\text { Actuated yaw force steered bogie (AY-FS) }\end{array}$ \\
\hline $\begin{array}{l}\text { Independent rotating } \\
\text { wheels }\end{array}$ & $\begin{array}{l}\text { Actuated independently rotating wheels } \\
\text { (AIRW) } \\
\text { Driven independently rotating wheels } \\
\text { (DIRW) } \\
\text { Directly steered wheels (DSW) }\end{array}$ \\
\hline
\end{tabular}

control, its vertical acceleration between 5 and $10 \mathrm{~Hz}$ can be suppressed. Then, LQG control with tuned weighting function turns out to be more effective for attenuating the first bending motion at $8.5 \mathrm{~Hz}$ than sky-hook control. In addition to this semi-active damper dealing with car-body flexible modes, the air spring with controllable orifice valve is applied simultaneously to cope with rigid motions at low frequency.

\subsection{Implementation of active secondary suspension}

\subsubsection{Implementation of active secondary suspension in lateral direction}

In the late 1970s and early 1980s, British Railways Technical Centre in the UK carried out a series of theoretical and experimental studies on active suspension [69]. The assessment methods for ride comfort and the limitations of passive suspensions were thoroughly analysed. Experimental tests for both vertical and lateral active suspension were undertaken considering different actuator technologies. In the vertical direction, electromagnetic actuators were mounted on a Mark III coach with BT10 bogies in parallel with the air springs. An alternative solution was also explored where an air pump actuator can vary the pressure and volume of air spring by an electric motor. According to the measured acceleration, around 50\% vibration reduction can be achieved at $1-2 \mathrm{~Hz}$. For the lateral active control, servo-hydraulic actuators were placed in parallel with air spring, and the vibration between 0.5 and $2 \mathrm{~Hz}$ was significantly reduced. A specially designed electro-mechanical actuator was involved in the field test for lateral active suspension and proved fail-safe when a failure of the control system occurred.

In the 1990s, Fiat Pendolino implemented a HOD function through pneumatic actuators in addition to tilting technology in operation. In a later stage, the centring function was integrated with the tilting devices [4].

In the mid of the 1990s, Siemens in Austria performed field tests on a prototype vehicle where tilting, lateral centring, and lateral and vertical semi-active technologies were put together [70-72]. The integrated active control strategy improved the overall dynamic performance.

KTH and Bombardier Transportation in Sweden have explored and developed active suspension in the program Green Train since 2005 [73]. Active lateral suspension and active vertical suspension were implemented on Regina 250 trains and tested in the line from 2007 to 2013 $[31,37,74]$. The HOD function was incorporated in the suspension to centre the car-body above the bogies in curves. The field tests were performed in curves with radii changing from $300 \mathrm{~m}$ to $3200 \mathrm{~m}$ showing that the maximum lateral displacement of the car-body could be reduced from $50 \mathrm{~mm}$ to $25 \mathrm{~mm}$, and significant improvement of ride comfort was observed as the contact of bump stop could be avoided. An active lateral suspension similar to the one tested in the Green Train project is now in use in the ETR1000 high-speed trains in Italy.

In recent years, Korea Railroad Research Institute carried out roller rig tests and field tests for active lateral suspension [75]. Electromagnetic actuators were implemented, and sky-
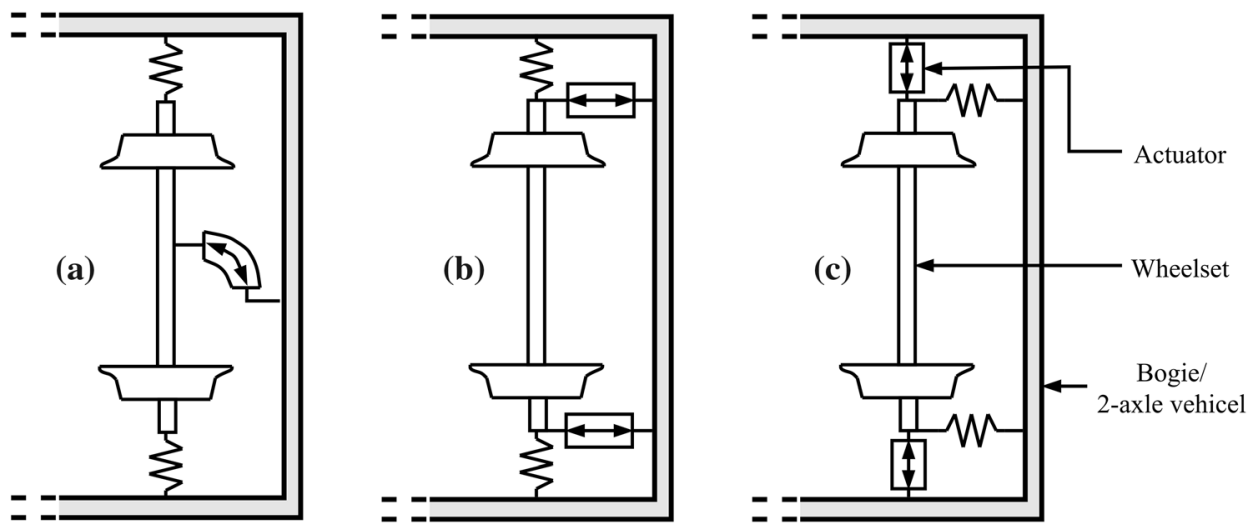

Fig. 22 General mechanical arrangements for actuated solid-axle wheelset (ASW) 

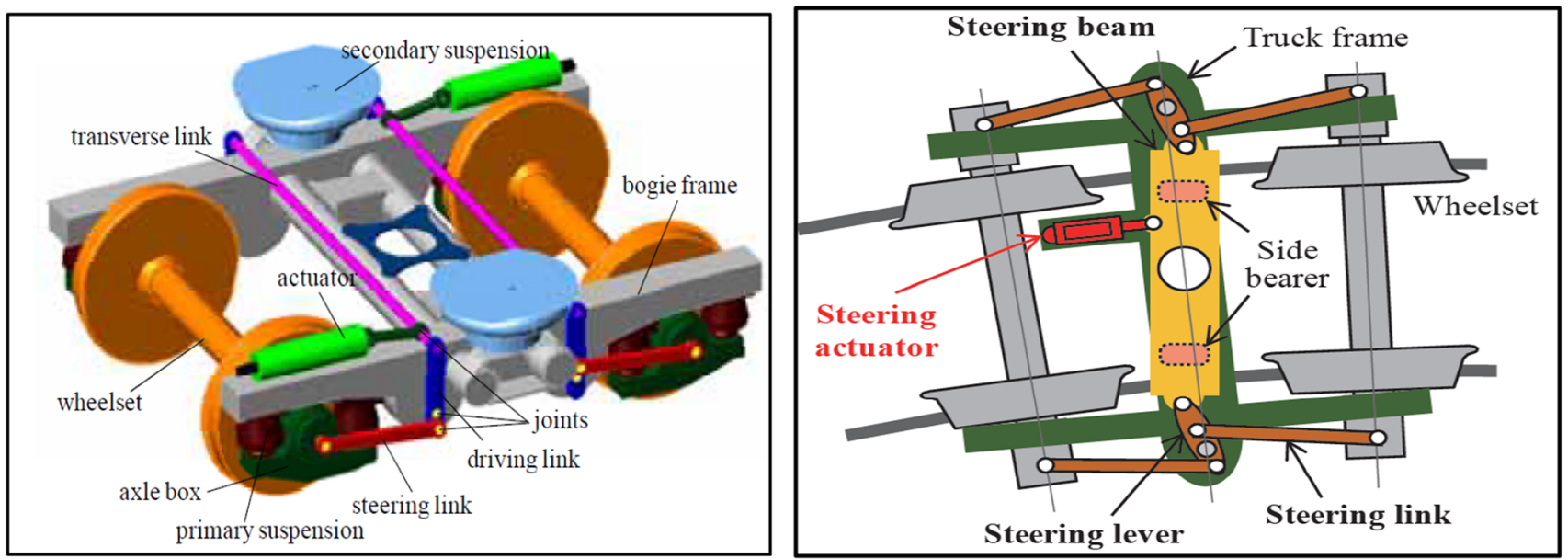

Fig. 23 Examples of steering schemes: active steering bogie with two actuators [93] (left) and active steering bogie with one actuator [94] (right)



Fig. 24 Yaw relaxation scheme [96]

hook control was applied in these experiments. Both urban vehicles and intercity vehicles were tested on a roller rig at $70 \mathrm{~km} / \mathrm{h}$ and $100 \mathrm{~km} / \mathrm{h}$, respectively. The lateral accelerations were reduced by $7 \mathrm{~dB}$ for both types of vehicle. The intercity vehicle was then tested on track at speeds of $90-100 \mathrm{~km} / \mathrm{h}$, showing a good agreement with measured results on rig tests. A fail-safe control scheme was proposed and examined in the field test. When the vehicle speed and actuator temperature signals exceeded beyond the 'yellow' or 'red' threshold, the control commands for active suspension were reduced $(60 \%)$ or deactivated. Redundant sensors were also implemented to achieve the fail-safe target as presented in Fig. 17.

Japan started the research for active suspension in the 1980s and has launched the first commercial train with fully active suspension in early 2000 .

In the beginning of the 1980s, the old Japanese National Railways (JNR) tested lateral active suspension with pneumatic actuators which halved the vibration at $120 \mathrm{~km} / \mathrm{h}$ [76]. After the privatization of JNR, the JR-East in 1991 made field tests on Series 400 EC train where pneumatic actuators and $H_{\infty}$ control were implemented for full-active suspension in lateral direction at maximum test speeds up to $240 \mathrm{~km} / \mathrm{h}$. In 1993 , a new field test on Star 21 with a maximum speed $425 \mathrm{~km} / \mathrm{h}$ was carried out. Both tests showed that $50 \%$ or more lateral vibration can be suppressed by active suspension. At the same time, JR West installed lateral pneumatic actuators in the test train WIN 350 and prototype of Series 500 EC [77]. Hitachi tested an active suspension with hydraulic actuators on WIN 350. Kawasaki Heavy Industries made field tests on the test Train 300X also with hydraulic active suspension based on the $H_{\infty}$ control law. These activities were the major field tests before the real implementation of active suspension. Research about rig tests and investigations of $H_{\infty}$ control in the same period can be found in $[50,78]$.

In 2001, the commercial operation of Series E2 and E3 Shinkansen trains started using fully active lateral suspension. In these vehicles, pneumatic actuators are implemented on the end cars and the green car (first class car). Semi-active suspensions have been installed in all cars [79]. $H_{\infty}$ control is adopted to eliminate the yaw and roll car-body vibrations. After that, the fully active suspension was further explored and developed in the project Fastech 360, aimed at developing higher speed trains. The test trains $360 \mathrm{~S}$ and $360 \mathrm{Z}$ had electromagnetic actuators with high bandwidth installed [80], while electro-mechanical actuators are applied in Series E5 and E6 in 2011 and 2013 [81].

\subsubsection{Implementation of active secondary suspension in vertical direction}

Regarding the active suspension in the vertical direction, extensive tests on a 1:6 scaled Shinkansen vehicle were performed by Kamada et al. [51-53]. In their studies, the 


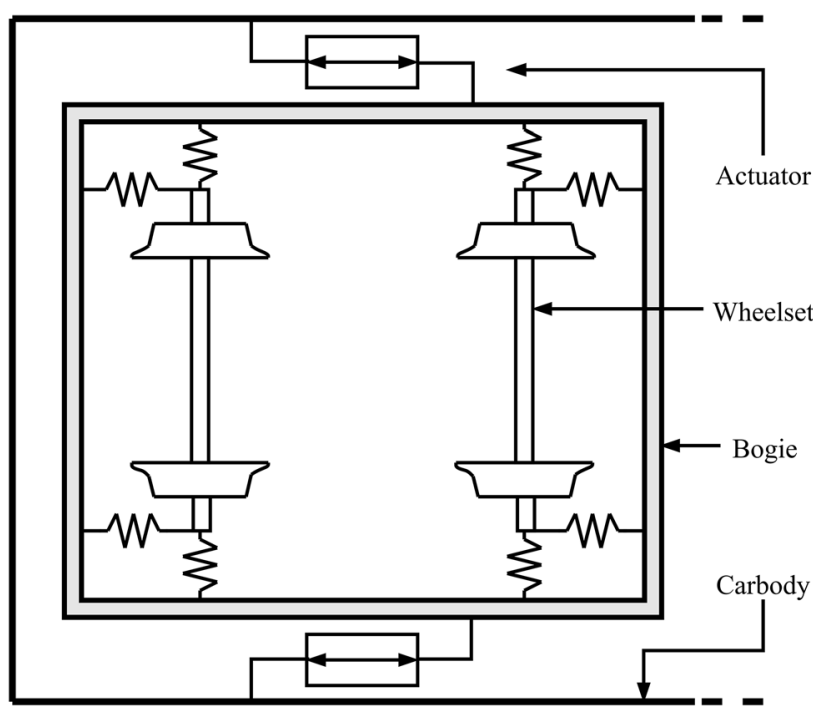

Fig. 25 Secondary yaw control (SYC)

control strategy applied was a robust $H_{\infty}$ modal control. The 1:6 scaled experimental set-up is shown in Fig. 18.

Firstly, five modes were considered: two rigid modes and three elastic modes [51]. A weighting function for disturbance suppression $\left(W_{s}\right)$ was chosen separately for each considered mode. A combination of linear and 20 stack piezoelectric actuators was used. The tasks were split between the two different actuators types. Linear actuators were used to control the two rigid modes while the piezoelectric ones were used to suppress the three elastic modes. Subsequently, the usage of pneumatic actuators in parallel with the air spring was considered [52]. Despite rigid body modes were effectively suppressed, the control performance became worse near the elastic vibration modes due to the nonlinearity of the electric-pneumatic valve. Lastly, air suspensions were directly used to control the first and second rigid modes and the first bending mode [53]. The air spring was controlled by adjusting the air pressure, and accelerometers were placed at the edges and the centre of the 1:6 scaled vehicle. Satisfactory results were obtained for the 1:6 scaled vehicle and for a simulated full-size vehicle. Here, a careful model of the pressure valve should be considered.

On-track tests of a vehicle with active vertical secondary suspensions were reported by Qazizadeh et al. [36, 37]. Here, secondary lateral and vertical dampers were replaced by electro-hydraulic actuators on the high-speed train Regina 250. A view of the actuator installation is given in Fig. 19.

A modal sky-hook approach was used on a two car-body train in which one car was equipped with conventional suspension and the other with the active devices. Accelerations were measured on the car-bodies above the



Fig. 26 Actuated yaw force steered bogie (AY-FS) [104]

secondary suspensions. The measurements were performed at speeds up to $200 \mathrm{~km} / \mathrm{h}$, showing $44 \%$ reduction of weighted vertical acceleration compared to the passive reference car.

\subsubsection{Implementation of semi-active suspension}

In the early 1990s, UK started an initial exploration of semi-active suspension on a test rig in GEC-Alstom Engineering Research Centre [82], with the purpose of studying the potential of semi-active damper in secondary lateral position. In the experimental work, a simplified scaled test rig was applied where an electro-hydraulic actuator produced excitation to simulate the bogie vibration. A two-state damper was realized by external pipework and solenoid valve enabling high and low damping. An interesting control strategy was proposed based on one single lateral velocity of the car-body. A threshold value was to switch between high and low damping rate. This switch damper scheme was shown to produce more than $25 \%$ improvement of the lateral ride index.

In the middle of the 1990s, on-track tests of secondary lateral semi-active suspension on a X2000 train set were carried out in Sweden [83]. A control strategy based on sky-hook law was applied to attenuate the lateral and yaw motions of the car-body. A mixed hydraulic and electromagnetic actuator was created to enable continuously variable damping rates. In the field test, semi-active devices were mounted on the driving trailer at the end of the train set. The RMS values of lateral acceleration decreased by $30 \%$ from 0.8 to $2 \mathrm{~Hz}$ but increased below $0.8 \mathrm{~Hz}$.

At around the same time, Austria Siemens carried out field tests for semi-active suspension [70-72]. Two lateral and two vertical hydraulic dampers with continuously adjustable damping valves were mounted on the vehicle in addition to the electro-mechanical tilting and pneumatic lateral positioning devices on the prototype bogie SF 600 . The ideal damping force was calculated based on sky-hook control, and a lookup-table method was used to produce 
demand current signals. Field measurements showed that the ride quality improvements in the range of $15 \%$ in terms of RMS acceleration.

In Korea, studies for semi-active suspensions through rig tests and field tests in the last decade were carried out in the last decade [84-88]. Shin et al. [84-86] carried out 1:5 scaled (Fig. 20) and full-scale [86] roller rig tests to study the effects of semi-active lateral suspension with MR dampers at different speeds. The classic sky-hook control and later $H_{\infty}$ control were applied to suppress the vibration. After that, a field test to evaluate ride quality was carried out [88]. The semi-active MR damper with skyhook control scheme could provide more than $29 \%$ improvement of weighted acceleration compared to the passive system.

Japanese researchers started to explore semi-active suspension technologies in the early 1990s and the technologies have been applied in commercial use since the end of the 1990s [77].

In 1994, JR-West used the test train WIN350 to explore the performance of semi-active suspension where 6-level variable dampers were implemented. The control was based on the sky-hook control law, showing 30\% vibration reduction at a speed of $300 \mathrm{~km} / \mathrm{h}$ with no influence on safety. Later, this system was implemented on Series 500 Shinkansen EC trains.

JR-Central installed semi-active suspension on Series 300 EC in 1994 for field tests, with similar variable dampers similar to the ones of JR-West. An improvement was achieved by introducing delay compensation and a bandpass filter to achieve a larger controllable frequency range. Series 700 Shinkansen EC trains have this system installed and are in operation since 1999.

To explore the concept of semi-active control for primary vertical damping introduced in Sect. 4.2.3, a Shinkansen vehicle was tested recently on a roller rig and in the line. Field tests were carried out on a line having a relatively poor track quality, to verify the effectiveness of the scheme $[27,39,89]$. The semi-active primary suspension can selectively reduce the vibration of the first bending mode of the car-body, and with tuned LQG controller, the rigid car-body motions can also be attenuated to some degree. The roller rig test and installation of semi-active damper are shown in Fig. 21.

\section{Active primary suspension}

\subsection{Solid-axle wheelsets versus independently rotating wheels}

For conventional vehicles with passive suspension system, a compromise between stability and curve-negotiation behaviour has to be made even if passive steering mechanisms are implemented [90]. In contrast, controlling wheelset kinematics by applying active suspension can provide flexible solutions to ensure stability and good curving behaviour at the same time. The implementation of active primary suspension is expected to produce greater monetary benefits than active secondary suspension due to its relation to the wheel-rail contact. The wear between wheel and rail will be significantly reduced and rolling contact fatigue tends to be improved, contributing to cost saving for both vehicles and infrastructures [91].

The wheelsets can be generally classified into two types according to their mechanical structures: Solid-axle wheelsets and independently rotating wheels. For solidaxle wheelsets, the two wheels rigidly mounted on the same axle will have the same rotating speed. Consequently, longitudinal creepage is produced enabling guidance and self-centring capability. However, longitudinal creepage causes hunting instability and undesired wear of wheel and rail during curve negotiation. In contrast, independently rotating wheels are free to have different rotational speeds leading to a virtual absence of longitudinal creepage, eventually losing guidance and self-centring ability and increasing the risk of flange contact.

In general, in the design of active primary suspensions, for solid wheelsets, 'stability' and 'steering' are two issues to be considered while for independently rotating wheels, 'guidance' is required too.

Because of the natural difference between solid-axle wheelsets and independently rotating wheels, it is intuitive to split the active primary suspension section into two parts. In Sect. 5.2, active solutions for solid-axle wheelsets

Table 2 Comparison of different schemes for perfect steering control

\begin{tabular}{ll}
\hline Control target & Measurement \\
\hline $\begin{array}{l}\text { Wheelset lateral displacement } \\
\begin{array}{l}\text { Zero yaw moment applied from } \\
\text { primary suspension }\end{array}\end{array}$ & Wheel conicity, curve radius, and lateral displacement of wheelset \\
$\begin{array}{l}\text { Ideal angle of attack } \\
\begin{array}{l}\text { Equal lateral displacement and angle } \\
\text { of attack }\end{array}\end{array}$ & $\begin{array}{l}\text { Curve radius, cant deficiency, creep coefficient, angle of attack } \\
\text { lateral and longitudinal deflection of primary suspension }\end{array}$ \\
\hline
\end{tabular}


Table 3 Comparison of three control strategies for stability

\begin{tabular}{lll}
\hline Control name & Input/measurement & Output \\
\hline Active lateral damping & Yaw angular velocity of the wheelset & Lateral force proportional to input signal \\
Active yaw damping & Lateral velocity of the wheelset & Yaw torque proportional to input signal \\
Sky-hook spring/absolute stiffness & Absolute yaw angle of wheelset & Yaw force proportional to input signal \\
\hline
\end{tabular}

are presented while solutions for independently rotating wheels are described in Sect. 5.3. Six configurations are considered in total and they are summarized in Table 1.

\subsection{Active primary suspension for solid-axle wheelsets}

\subsubsection{Principles and configurations}

\section{(a) Actuated solid-axle wheelset (ASW)}

For solid-axle wheelsets, ASW is the most extensively studied configuration where either yaw torque or lateral force is applied directly to the wheelset to control the yaw and lateral motions so that curve negotiation and stability will be improved [3]. This principle can be realized by three general mechanical arrangements. Yaw torque could be applied directly by one yaw actuator mounted between bogie and wheelset as shown in Fig. 22a or in a more practical way utilizing two actuators in the longitudinal direction at the ends of the wheelset, as indicated in Fig. 22b. Since wheelset yaw motion and lateral motion are coupled, implementing lateral actuators (see Fig. 22c) is another way to achieve the motion control of the wheelset. However, a study [92] based on a simplified two-axle vehicle model concluded that the lateral actuation requires a larger force to achieve the same stability of the vehicle than the yaw actuator. Moreover, when this scheme is used, a deterioration of the ride quality can be expected and the installation space for lateral actuators would be an issue.

Among the three schemes, arrangement (b) is the most favourable idea from which some new specific schemes have been proposed as shown in Fig. 23.

In the left scheme shown in Fig. 23, introduced by Park et al. [93], each wheelset has one longitudinal actuator. The mechanical linkages are designed to transfer the mutually opposite actuation force on the left and right ends of each wheelset. Therefore, there is only one actuator implemented for each wheelset. In the right scheme, introduced by Umehara et al. [94], a more elaborately designed set of connecting rods couples the front and rear wheelset motion so that only one actuator is required for each bogie to achieve the steering effect. Reducing the number of actuators by introducing articulated mechanical linkages can save installation space and cost for actuation system. However, implementing fewer actuators means higher performance requirements for each actuator, such as higher maximum force and maximum pressure, but it still has potential to improve the reliability of the whole system. When the number of actuator is reduced, the installation space and cost can be saved for fault-tolerant actuators with redundant structures. This is an important aspect in the practical design process [95].

In the concept of 'yaw relaxation' [96], as shown in Fig. 24, a spring is arranged in series with a longitudinal actuator connecting the axle to the bogie frame. On tangent track, the stability is ensured by the passive spring and high stiffness of the actuation system working in low bandwidth frequency range or passive mode. In curves, the actuation works in active mode and can steer the wheelset with low force.

If the primary spring remains in parallel with yaw actuators in the longitudinal direction to ensure the stability of the vehicle, a higher actuation force is required to cancel out the action of the passive spring in curves. However, having a passive suspension in parallel to the actuator is an efficient approach to guarantee fault tolerance of the active suspension, which is crucial for the implementation of ASW [95]. In real design of a primary suspension, longitudinal stiffness of the passive spring is difficult to be completely removed, because of the existence of either coil spring or rubber spring required to bear the vertical load. Nevertheless, reducing conventional longitudinal stiffness is instrumental to achieve lower actuation force as shown in $[97,98]$.

\section{(b) Secondary yaw control (SYC)}

Secondary yaw control was firstly proposed by Diana et al. in order to improve stability in tangent track and curving performance of a tilting train [99, 100]. Yaw torque from car-body to bogie is produced by two longitudinal electromechanical actuators in the position where the original passive yaw damper is mounted. This scheme is also called active yaw damper (ADD, in German: 'aktiver Drehdämpfer'). A schematic of this concept is shown in Fig. 25. The concept SYC can enhance the vehicle critical speed and reduce track shift forces. Since the motion of the wheelset is uncontrolled, the steering effect is not as effective as ASW, but the improved stability can allow lower primary yaw stiffness and consequently lead to an improvement of the curving performance. Although it is 

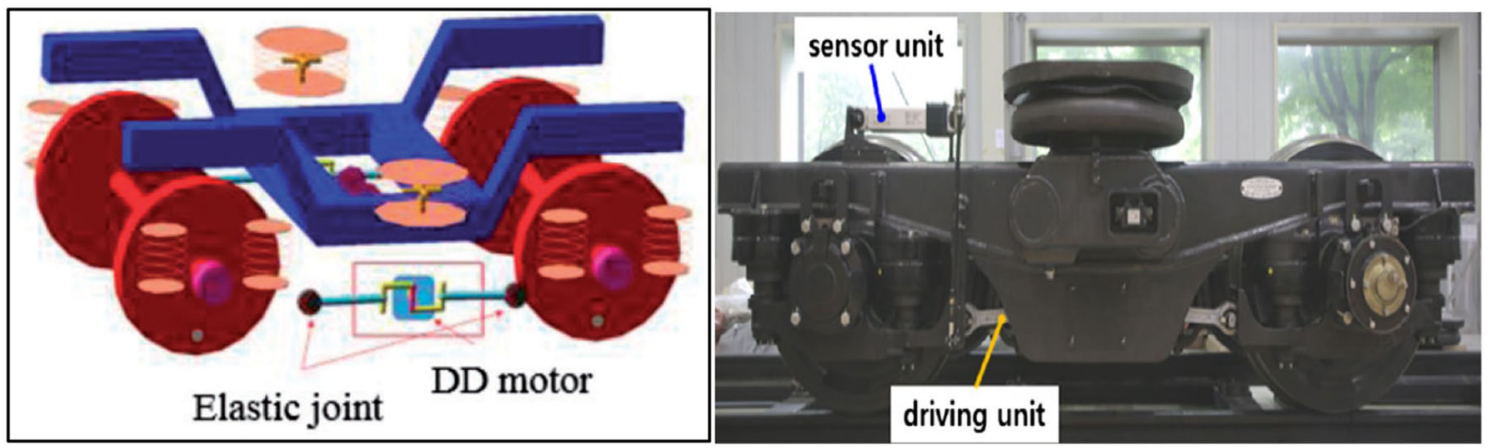

Fig. 27 Actuator device for steering [97] (left) and prototype of steering bogie [107] (right)

reasonable as well to classify the SYC into active secondary suspension, the target of SYC is to improve stability and reduce track shift forces in curves rather than improving ride quality. Therefore, this control scheme is closer to the nature of active primary suspension.

Sharing the similar idea of SYC, a new active control for a bogie is proposed to improve the stability as is introduced in [101]. In this work, two inertial actuators are applied in lateral direction on the front and rear beam of the bogie frame. Simulation results proved the enhancement of stability and recently a scaled roller rig test demonstrated a reduced lateral displacement of the bogie [102].

\section{(c) Actuated yaw force steered bogie (AY-FS)}

Based on SYC, a new active suspension AY-FS was proposed by Simson for heavy hauling locomotives [103-105]. In this concept, force steering linkage is implemented with SYC. It can be seen as a combination of SYC and passive steering linkages through which wheelsets can be forced into an ideal position according to the kinematic relationship between bogie and car-body, as presented in Fig. 26. This concept can significantly improve the curving behaviour of locomotives with high tractive effort.

\subsubsection{Control strategies for steering and stability}

The control strategy varies according to the control targets, from which different strategies are classified into two main categories: (a) control strategies for steering and (b) control strategies for hunting stability.

\section{a. Control strategies for steering}

The fundamental objective of implementing an active primary suspension is often to improve the curving behaviour. Wear number/wear index and equality of track shift force among different wheelsets are often used to assess the vehicle's curving behaviour. Different principles of steering introduced in literature are summarized below: (a.1) Radial control, (a.2) Perfect control, (a.3) Steering control in locomotives, and (a.4) Other controls

\section{a.1 Radial control}

The idea of radial control is to steer each wheelset to achieve a radial position in curves. In other words, the attack angle of wheelset should be as small as possible. Based on this idea, some schemes of steering bogies by means of passive linkages or coupling of wheelsets have been proposed. Well established is for example the design of Talgo [106]. However, theoretically this control concept produces perfect curving behaviour only when cant deficiency is zero which seldom is the case in real operation. An appropriate small angle of attack is needed to produce lateral creep force that can balance the un-compensated lateral force in normal cases. Despite its simplicity, this control scheme has been shown to provide significant improvement for curving behaviour [107].

\section{a.2 Perfect steering control}

The perfect steering defined by Goodall and Mei [59] points out that the longitudinal creep forces on wheels on the same axle should be equal to zero if no traction or braking force is applied. Meanwhile, the equal lateral creep force on each wheelset should be achieved. However, in operation, direct measurements of creep forces are very difficult. Therefore, some equivalent indicators that can be formulated for perfect steering conditions are proposed and summarized as below.

- Perfect control based on wheelset lateral position

Zero longitudinal force (without traction and braking force) and equal lateral forces mean pure rolling of each wheel. To achieve the pure rolling, a yaw torque can be applied to control the lateral position of the wheelset $[108,109]$.

Under the assumption that the wheel is a straight cone [93], the needed lateral displacement of the wheelset can be calculated according to Eq. (7): 
$y=\frac{e r_{0}}{\lambda R}$,

where $e$ is the half track clearance; $r_{0}$ represents the rolling radius; $\lambda$ refers to the wheel conicity, and $R$ is the curve radius. In this control, wheel conicity and lateral displacements of the wheelset may be difficult to measure or estimate. The approach was used for a two-axle vehicle where a scaling procedure based on vehicle speed and estimated curvature was applied to improve the stability of a PID controller in different running conditions [110].

- Perfect control based on yaw moment applied from primary suspension

This control strategy was first proposed in the previously mentioned yaw relaxation method by Shen and Goodall [96] and some following studies were carried out by Perez and Shen, respectively [108, 109].

The force applied on the wheelset can be divided into two parts: the force from the wheel-rail contact, and the force transmitted from the bogie through the primary suspension. The two creep forces pointing in opposite direction on the two wheels exert a yaw torque but in the ideal steering condition this torque should be zero. If the inertia force of the wheelset is neglected, the yaw torque generated by the primary suspension should be reduced to zero. In other words, to make the wheelset take the pure rolling position, the yaw motion of wheelset is set to free. Therefore, this control is also known as yaw relaxation. The measurement of this yaw torque can be realized by calculating the longitudinal forces applied on the axle box. The actuation force could be measured from the actuation system, and the spring force could be obtained by measuring the deflection of the springs and the knowledge of the stiffness characteristics. A measurement error could be introduced because stiffness varies at different load levels.

- Perfect control based on ideal angle of attack

Equal ideal angle of attack for each wheelset is another indicator for equal lateral contact force on both wheelsets in a bogie [109]. The ideal angle for each wheelset is determined by track data (curvature and super-elevation), cant deficiency (vehicle speed) and creep coefficient. Feedforward control could be implemented to simplify the control design and avoid instability of the system. However, many inaccurate measurements of these parameters and uncertainty of primary suspension stiffness can cause ineffectiveness of the control. Therefore, the application of feedback control will improve the effectiveness of steering.

- Perfect control based on same position/movement of wheelsets

In this control strategy, neither ideal angle of attack nor ideal lateral displacement is required. Instead, zero difference of the angle of attack and lateral displacement between the wheelsets is prescribed as the control target. The force or deflection of the primary suspension in lateral and longitudinal direction can be measured as alternative solution to eliminate the difference of wheelsets motions.

In summary, the above-mentioned four strategies are all based on the same principle about creep forces. In the ideal condition that all the parameters can be accurately measured, all four control strategies can provide perfect steering effect. If sensing issues and uncertainty of measurement are considered, the steering effect of these control strategies could be deteriorated and present different characteristics. Table 2 compares the above control schemes.

The above four control strategies are proposed because of the difficulty to measure creep forces. With some specific filtering methods being proposed for estimation of creep forces [111], the estimated creep forces can be directly considered as a control target to achieve the perfect steering control [98].

\section{a.3 Steering control in locomotives}

Even though perfect steering in (a.2) can be applied in a abroad range of railway vehicles, it may not be suited well for hauling locomotives. Because of the significant tractive effects in longitudinal directions, heavy haul trains in curves have longitudinal and lateral forces on couplers which will generate a yaw moment [103]. However, this moment cannot be balanced in the concept of perfect steering where equal longitudinal and lateral creep forces are required.

Given that, Simson et al. proposed two steering principles for locomotives. 'Modified perfect locomotive steering' was firstly proposed as modification of perfect steering. It requires equal longitudinal creep force at each wheel and equal lateral creep force for the wheelsets in the same bogie. In other words, it allows different lateral forces generated from front and rear bogies so that the yaw moment can be balanced. However, the equality of longitudinal force will limit the utilization of adhesion, as the vertical load of each wheel varies in many operations.

To solve this problem, 'Ideal locomotive steering' was proposed where the requirement for equality of longitudinal creep forces is released but its direction should be kept the same as the traction force. This strategy allows more flexible positions of the wheelset and can minimize the creep forces. Moreover, flange contact can be avoided effectively even in tight curves and the risk of derailment is said to be reduced [103].

\section{a.4 Other controls}

For the scheme SYC, reducing/equalizing track shift forces of the two axles on the same bogie is the major control target. When the vehicle passes a specific curve radius with 
a particular non-compensated acceleration, the reference actuation force will be obtained from a lookup table derived from a large number of simulations considering different operational scenarios [100].

Regarding the scheme AY-FS, a reference yaw angle of the bogie can be calculated according to the position of the bogie in the curve. A PID controller is introduced to achieve the target angle. The control idea based on sensing longitudinal forces can be found in [104, 105].

\section{b. Control strategies for hunting stability}

The self-excited oscillation of solid-axle wheelset introduces hunting instability of the vehicle system. Achieving stabilization is the primary interest of active primary suspension apart from steering. The yaw angle, lateral velocity and yaw angular velocity of the wheelset are three indicators for wheelset instability. Three corresponding control strategies are proposed to stabilize the kinematic modes of the wheelset.

Active lateral damping and active yaw damping are two similar control strategies. The former one applies a lateral force that is proportional to the yaw velocity of the wheelset, while the latter one introduces yaw torque proportional to the lateral velocity of the wheelset. The stabilization effects of these two control strategies are theoretically verified in [3] based on a model of a two-axle vehicle. The active yaw damping is preferable to active lateral damping as it requires lower actuation force and can produce better ride quality [92]. The active yaw damping effect was also validated with tests by Pearson et al. [112].

The third stability control strategy named 'Sky-hook spring' (also known as 'Absolute yaw stiffness') is inspired by the ineffectiveness of passive yaw stiffness [44, 113]. In a passive primary suspension, springs produce yaw force that is proportional to the relative rotation between bogie and wheelset, but an ideal yaw force should be proportional to the absolute yaw motion of wheelset. Increasing stiffness of the spring can enhance the effect of yaw force and thereby the stability will be improved, but the effect will still be deteriorated by the motion of the bogie. In order to solve this issue, 'Sky-hook spring' was proposed [113]. The yaw force acting on the wheelset is proportional to the measured absolute yaw angle of the wheelset with a highpass filter to remove the low-frequency signal from curving. Table 3 presents the above three control strategies.

In SYC, the stabilization of the vehicle is achieved by two longitudinal actuators used to mimic secondary yaw dampers. The reference forces of actuators can be calculated according to Eq. (8):

$F_{\text {ref }}=-\left(c_{\mathrm{v}} v_{\text {rel }}+m_{\mathrm{v}} a_{x}\right)$,

where $v_{\text {rel }}$ is relative velocity between bogie and car-body and $c_{\mathrm{v}}$ is a gain like viscous damping. The delays from sensors and action of the actuator are compensated by introducing term $m_{\mathrm{v}} a_{x}$ [100].

The control principles for stability and steering are separately summarized above, while the control of actuator behaviour can also be realized by adopting a controller like $H_{\infty}$. The efficiency of $H_{\infty}$ has been investigated for a conventional bogie vehicle (Mousavi et al. [114]) and twoaxle vehicle (Qazizadeh et al. [115]), where the improvement of curving performance can be achieved with reduced actuation force.

\subsubsection{Implementation}

Except for the concept of SYC, there is no commercial application of active primary suspension, but significant new progress has been made since the last review work in 2007 [4].

SYC has been tested on a full-scale roller rig and track $[99,100,116]$ in the early 2000's. Reduced wheelset guiding force and improved vehicle stability were confirmed in the tests. Siemens has implemented active yaw damper (ADD) into electric locomotives (types ES64F4 and ES64U2 [117]) and intends to use this system for the new locomotive generation 'Vectron'.

In recent years, the concept of ASW received more attention. In the following, roller rig tests and field tests carried out in different countries are described.

Umehara et al. [94] developed a steering truck based on the scheme shown in Fig. 23 right. For each bogie, there is only one electro-hydrostatic actuator (EHA) which is designed through special circuit and valves to rule out any risk of inverse control of actuators [118]. If inverse steering occurs, the actuator will produce no force, i.e. the actuation system is fail-safe. A test was carried out at $10 \mathrm{~km} / \mathrm{h}$ on tangent track to validate the fail-safe function of the EHA actuator, showing no increase in wheelset guiding force in case of inverse steering control.

At around 2010, the Korea Railroad Research Institute carried out an experiment on a 1:5 scaled roller rig test based on the mechanical arrangement shown in Fig. 23 left [93]. A perfect steering control based on ideal lateral displacement of the wheelset was implemented, with the assumption of perfectly coned wheels. Electromagnetic linear actuators are applied in this experiment. The test demonstrated improvement in terms of wheelset lateral displacement and guiding force.

After this work, a series of studies focusing on a new steering arrangement were performed ranging from simulations to on-track tests. The control strategy is based on the radial position of wheelset in curves as introduced in Sect. 5.2.2 (a.1). A real-time curve radius estimation method is proposed where the only measurement is relative displacement between two points from car-body and bogie, 
respectively [97]. A special electro-mechanical actuator was created in which the rotation of a drive motor is used together with linkages to achieve the linear motion of rods at both ends, as shown in Fig. 27 (left), different from a conventional linear actuator. By doing so, there is only one actuator device at each side of the bogie. Additionally, a primary rubber spring is redesigned to achieve lower longitudinal stiffness. Figure 27 (right) presents the prototype of the steering bogie, which was firstly put on track for a stationary experiment to examine the movement of the actuation system [119]. The curvature signal measured in advance was sent to the control system to simulate the real track information, and then, measurements were carried out for yaw angle of wheelset and actuation force. Considering maintenance and cost of the yaw angle measurement system, a feedforward control is adopted for controlling the displacement of the actuator. Therefore, the measurement of the wheelset yaw angle is only to assess the wheelset movement. The maximum error between reference steering angle and the measured one is $8 \%$. Moreover, the controller has a self-diagnosis function. When an error signal is identified, the actuation system will switch into passive bogie mode.

A recent publication [107] presents experimental results carried out on a commercial line. The curvature estimation and steering angle are satisfactory with a maximum error of $2.4 \%$ and $4.9 \%$, respectively. The wheel lateral force is significantly reduced, and a total of $1000 \mathrm{~km}$ test runs showed negligible flange wear on the wheels.

In China, CRRC has presented a prototype of the next generation of metro vehicle 'Cetrovo' which is equipped with an active steering system [120]. Dr. Wang Xu, a senior engineer in R\&D Center, CRRC Qingdao Sifang Co. Ltd. presents us the recent progress. The steering system adopts hydraulic servo actuators. The reference displacement of the actuator is computed according to the track curvature that is obtained through the utilization of track curvature database and geo-localization technology. Initial field tests have been finished recently, showing significant improvement in terms of wheelset guiding force and noise from the wheel-rail contact.

Bombardier has developed a double-deck train called TWINDEXX [121] where active steering is implemented. However, no further technical information has been published so far and the current development status is unknown.

It should be noted that when approaching the final implementation of active primary suspension, a serious look at fault tolerance of active suspension systems should be taken. While beneficial effects have been confirmed, safety critical issue must be dealt with properly at the same time. Some fail-safe designs have been made in the above- mentioned works. In the future, continuous attention should be put on fault-tolerant design of actuation system.

\subsection{Independently rotating wheels}

Apart from implementing active primary suspension for solid-axle wheelsets, independently rotating wheels is another solution to overcome the well-known trade-off problem between running stability and curving performance. Compared to solid-axle wheelsets, a change in the wheelset configuration enables the wheels on the same axle to independently rotate with respect to each other. In this way, the dependency between the yaw and lateral movement of the wheelset is removed, virtually eliminating the longitudinal creep force at the wheel-rail interface. Thus, pure rolling is no more dependent on the lateral position of the wheelset, which significantly reduces wear and also inhibits hunting motion (Goodall and Mei [122] and Pérez et al. [123]). Additionally, if the use of two-axle railway vehicles is considered together with IRWs, as described by Kurzeck and Valente [124] for the 'Next Generation Train' (NGT) project, a double-deck train set configuration with continuous low floor is possible. One of the first applications of IRW was presented in 1941 by Talgo in which passive steering capability was achieved by linkages between wheels [106]. Talgo's first solution is shown in Fig. 28. IRWs are also applied to low speed applications such as tramways [125].

Nevertheless, some drawbacks are generated when the constraint between the wheels is removed. The absence of coupling between the wheels leads to the loss of the selfguidance ability [122, 123] that will eventually lead to flange contact. It is further demonstrated by Goodall and Mei [122] through the usage of a linearized model of a twoaxle vehicle that dynamic instability is still present for the IRWs configuration. Moreover, the longitudinal creep

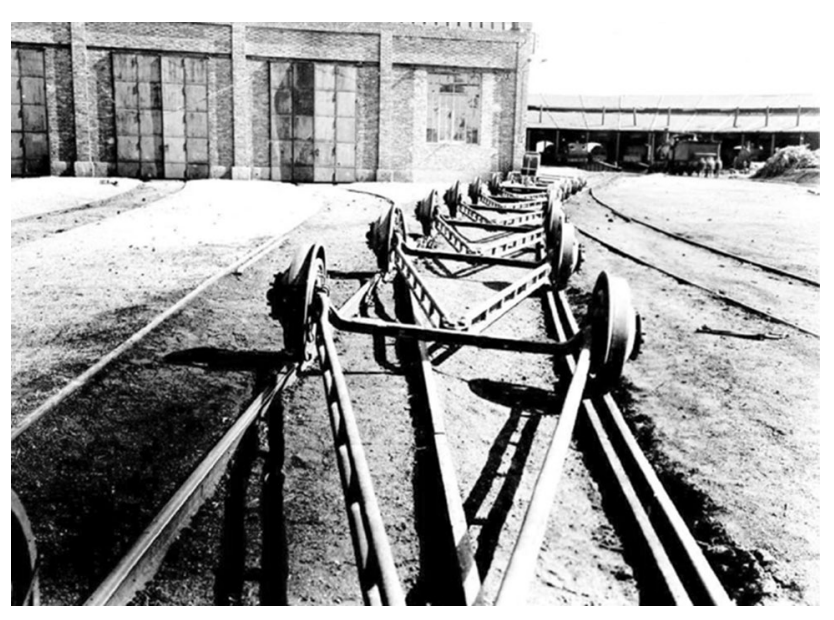

Fig. 28 Talgo solution of 1941 [106] 




Fig. 29 Actuated independently rotating wheel (AIRW)

forces on the wheel-rail interface cannot be completely removed and can still affect the stability of the wheelset $[126,127]$. Active solutions for IRWs were first introduced by Mei and Goodall [3, 92]. The absence of self-guidance capability and the risk for dynamic instability will lead to poor ride, noise and wear, and must be addressed, either by passive design as done by Talgo or by active control. This aspect is clearly pointed out in the literature by Mei and Goodall [92], Goodall and Mei [122] and Gretzschel and Bose [128].

In order to achieve guidance and stability, different types of mechatronic configurations of the IRW can be used. As defined by Bruni et al. [4, 129] and subsequently adopted as definitions, it is possible to divide the active primary suspension related to the IRWs in three main categories: AIRW [92], DIRW [128] and DSW [130].

Other passive designs than Talgo's one exist (differential coupling wheelset [131], apparently independently rotating wheels [132], inverse tread conicity [133]), but they are not concern of this work.

\subsubsection{Principles and configurations}

\section{(a) Actuated independently rotating wheel (AIRW)}

The concept of AIRWs (Fig. 29) is based on the possibility of controlling the yaw and lateral displacement of the common axle on which the independently rotating wheels are mounted with an external actuator. This can be done either by the direct application of a torque to the axle (Goodall et al. [122, 134, 135] and Mei et al. [136]), or use of a linear actuator (Pérez et al. [123, 137]). The example of Fig. 29 shows this last possibility. The possibility of using a semi-active approach was shown by Mei et al. [8] where MR dampers are considered. Using a two-axle linear model, it was proved by Mei and Goodall [92] that the torque required to steer the AIRW is lower than the one

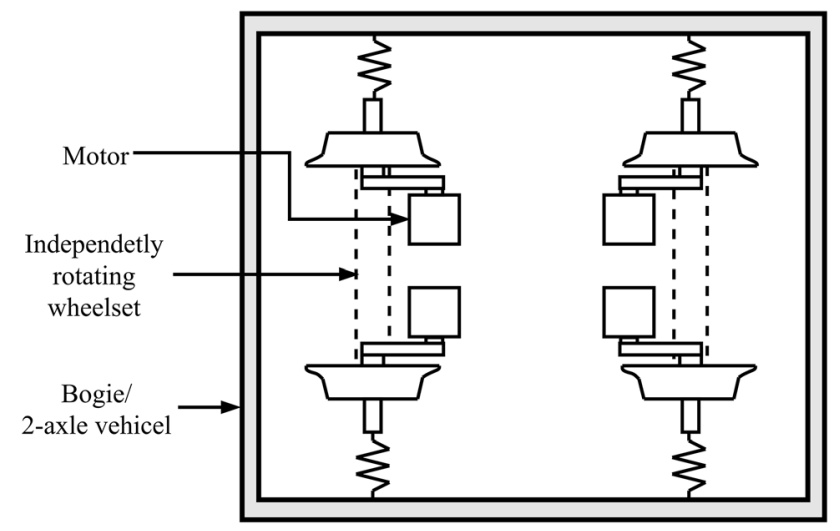

Fig. 30 Driven independently rotating wheel (DIRW)

required by a solid-axle vehicle due to the early zero longitudinal creep forces. A combination of AIRW and DIRW was though presented by Perez et al. [137].

(b) Driven independently rotating wheel (DIRW)

The concept of DIRWs (Fig. 30) is based on the possibility of controlling the speed of the two wheels of one axle autonomously. This was done firstly by applying a differential torque provided by electric servomotors through a gearbox connecting the two wheels by Gretzschel et al. [128, 138]. More recently, thanks to the advances in asynchronous induction motor control methods, an AC motor is assigned to each wheel. These are then used to provide traction, wheel guidance and stability control. The motors can be externally mounted and connected to the wheelset through a gearbox (Pérez et al. [137], Liang et al. [139, 140], Ahn et al. [141], Lu et al. [142] and Farhat et al. [98, 143]) as shown in Fig. 30 or embedded inside the wheels (Mei et al. [144], Ji et al. [145] and in the 'Next Generation Train' project in [124], [146-149]). The absence of additional actuators leads to a reduction in the space required by the wheelset frame, and to the possibility to provide both traction and control within the same system reducing cost and improving reliability. The DIRW solution is therefore an attractive solution and has been the subject of extensive studies in recent years.

\section{(c) Directly steered wheels (DSW)}

The concept of DSW (Fig. 31) involves the removal of the common axle between the wheels which is replaced by a frame on which the two wheels connected by a track rod are mounted. In this way, the two wheels can be directly steered. An actuation can be provided applying a displacement to the steering rod (Aknin et al. [130] and Wickens in [150], [151]) as shown in Fig. 31 or by applying a differential torque through hub-mounted traction motors (Powell in [152]). A configuration of DSW having self- 




Fig. 31 Directly steered wheels (DSW)

steering capability was presented by Michitsuji et al. [153-155]. It was also shown by Wickens in [151] that the stability issue achieved through active control is less affected by friction and traction than with other types of active control. Nevertheless, this idea is one of the less studied.

\subsubsection{Control strategies for stability and guidance}

In this section, the control strategies proposed to solve the stability and guidance problems are discussed in the perspective of: (a) stability control and (b) guidance and steering Control.

\section{(a) Stability control}

Stability control is aimed at increasing the running speed of the vehicle by reducing unstable wheelset motion that may occur. When necessary, in IRW, stability control needs to be applied in conjunction with guidance control. In fact, as mentioned above, the lack of the self-centring mechanism in IRWs makes the presence of active guidance control strongly recommended when passive solutions are missing. The stability problem is particularly evident when the longitudinal suspensions are removed. Although both AIRW and DIRW can share some control strategies, this is not generally valid for the DSW due to its peculiarity.

\section{a.1 Differential yaw rate feedback}

The yaw speed difference approach to IRW stabilization concerns the actuated type (AIRW). Nevertheless, it is possible to apply it on different types of IRW. This approach was introduced by Goodall and Mei [122]. Here, yaw damping for each wheelset is actively introduced in the system through the feedback of the difference between the wheelset and bogie/car-body yaw velocity. This choice is done to simplify sensing issues in the implementation of the concept. Moreover, in his studies Goodall proposed the adaptation of the control effort based on the train speed [122], [135]. Subsequently, Mei and Goodall in [134] developed an $H_{\infty}$ control using $\mu$-synthesis based on the same concept as described above. This is to overcome the problem of parameter variation, non-modelled actuator dynamics and the necessity of a simple model to describe the complexity of a real train. The concept was further investigated by Mei et al. [8]. A semi-active approach using MR dampers is used observing that the required control effort is much lower than what is needed for a solid axle with the same control objective. Moreover, only the feedback signals that are in phase with the control force can be considered [135]. The stability problem was less crucial in the work by Perez et al. [123, 137] because of the consideration of a conventional bogie vehicle with longitudinal suspension.

\section{a.2 Absolute yaw rate feedback}

Absolute yaw rate feedback provides stability to DIRW by controlling the rotational speed of the two wheels through a common gearbox or the differential torques provided by independent wheel motors. The first approach was introduced by Gretzschel et al. [128, 138]. In this work, stability and guidance are considered at the same time. The yaw velocity of the leading axle together with the front and rear axle lateral displacements are fed back into a common PID controller that sets the direction and the amount of torque to be produced by the steering motor through a gearbox that connects the two wheels on the same axle. The same approach was studied by Liu et al. [156], where cascade PID controllers are used instead of the common PID approach. Here, each wheelset is controlled by a separate cascade control scheme and differential torque control is applied instead of a common gearbox.

\section{a.3 Absolute yaw stiffness}

Absolute yaw stiffness is aimed at increasing the stability of the IRW by actively introducing yaw stiffness through the feedback of the yaw angle. This approach relies on the possibility to measure the yaw angle which might not be feasible in real applications. Absolute yaw stiffness for DIRW was introduced by Mei et al. [144] where wheel embedded permanent magnet synchronous motors are used. The desired yaw stiffness is achieved through the differential torque generated by the two motors. The yaw angle measurement is high-pass filtered to influence only kinematic behaviours and not interfere with the quasi-static ones, such as guidance and curving action. Based on the same principle, the stability action for this control was tested in a test rig and compared with simulation results by Liang and Iwnicki [139, 140]. 
Table 4 Comparison of different schemes for stability control on IRW

\begin{tabular}{llll}
\hline Control strategy & Control target & Measurement & Application \\
\hline Differential yaw rate feedback & Introduce damping & Bogie/car-body and IRW yaw velocity & AIRW \\
Absolute yaw rate feedback & Introduce damping & IRW yaw velocity & DIRW \\
Absolute yaw stiffness & Introduce stabilization longitudinal stiffness & IRW yaw motion & DIRW \\
\hline
\end{tabular}

\section{a.4 DSW}

Concerning the DSW configuration, stabilization is achieved by simply applying guidance control with a large stability margin with respect to the speed as shown by Wickens in [150, 151]. In [151], Wickens compared stability limits of conventional passive vehicle, yaw relaxation control, ASW and DSW showing that only for the DSW configuration no stability limits exist for speed and equivalent conicity variation.

The comparison among above-mentioned schemes for stability control is summarized in Table 4.

(b) Guidance and steering control

Guidance control is necessary when high-speed applications of IRW with absence of otherwise passive solutions are considered, especially considering AIRW and DIRW. As mentioned before, guidance control is aimed at actively restoring the self-steering mechanism and provides steering capability. Often, guidance control is applied together with stability control. As mentioned in the stability control section, the DSW configuration relies on different approaches with respect to the other two configurations. In fact, mechanical configurations are generally preferred for DSW to restore the self-centring capability.

\section{b.1 Equal wheels speed}

Controlling the two wheels to have the same speed will mimic the behaviour of a wheelset with solid axle. In this way, guidance and self-centring mechanism are restored leading though to the possibility of facing the same problems affecting a solid wheelset. This approach was proposed by Goodall et al. [122, 135] for AIRW. The external actuator will steer the IRW wheelset such that the speed difference of the two wheels is set to zero. The problem of adaptation was introduced too. As mentioned for the stability part, an $H_{\infty}$ control using $\mu$-synthesis was subsequently developed in [134]. Concerning DIRW, the same approach can be used where the wheel speed difference is controlled directly through the wheel motors. $\mathrm{Ji}$ et al. [145] studied the dependency between the synchronous motors control accuracy and the rail-wheel clearance, proposing an optimized tread profile to reduce this dependency. A model of the synchronous motors is introduced where torque ripples generated by non-uniform magnetic field and stator high harmonics currents are considered. Liu et al. [156] combined absolute yaw rate feedback (1.b) with the equal wheels speed control in a cascade PID control. Enhancement of the vehicle's running behaviour is found when the cascade control is applied with respect to the application of the equal wheels speed control alone.

\section{b.2 Nonzero lateral clearance}

Concerning AIRW, an approach to restore guidance was proposed by Pérez et al. [123, 137]. To avoid flange contact lateral clearance is set to zero. Because of the impracticality of measuring the lateral displacement of the wheelset with respect to the track centre line, a reference signal for the wheel speed difference based on the curvature of the track and the velocity of the train is derived. The reference value is obtained from the dynamic equations that describe the system. The wheels speed difference is found to be related to the rest of the variables by a first-order transfer function with low time constant that allows to neglect this contribution in the frequency range of the guidance control. The relation is then further simplified by considering the quasi-static condition during curving. The simplifications done eventually lead to an error of the obtained lateral displacement with respect to the centre line.

\section{b.3 Zero lateral clearance}

An alternative approach to the nonzero lateral clearance is often applied. Here, the IRW is controlled to be at the centre line and thus having a zero lateral clearance. This kind of approach involves the necessity of measuring the lateral displacement of the wheelset or the usage of estimation procedures. This approach is generally applied to DIRW where additional feedback variables may be introduced. Within the 'Next Generation Train' project, a PD control was used by Kurzeck et al. [146] to implement the zero lateral clearance approach. In his study, Kurzeck focused on the peak torque and power required due to track irregularities. Here, a torque limiter is introduced, and a pattern search optimization is used to tune the controller with the objective of reducing the wear in curved track with irregularities. Using the same control approach but focusing on the synchronous motor control, Ahn et al. [141] successfully showed the effectiveness of this control scheme on a 1:5 scaled test rig. A feedforward action was introduced by Grether in [147] to compensate the 
Table 5 Comparison of different schemes for guidance control on IRW

\begin{tabular}{llll}
\hline Control strategy & Control target & Measurement & Application \\
\hline Equal wheels speed & Creation of a solid-like wheelset & Wheels rotational velocity & AIRW/DIRW \\
Nonzero lateral clearance & Avoid flange contact & Wheels rotational velocity & AIRW \\
Zero lateral clearance & Avoid flange contact & IRW lateral displacement & DIRW \\
Differential traction control & Equal contact forces on the two wheels & Motor torques & DIRW and AIRW \\
\hline
\end{tabular}

gyroscopic moment introduced into the system in transition curves. This concept was then used by Heckmann et al. [148] in combination with a feedback control on lateral displacement, yaw angle and yaw velocity of the wheelset. In his work Heckmann also introduced a gain-scheduling approach based on the vehicle velocity to avoid possible control instability caused by speed variation. A preceding control was then implemented to improve the performance of the rear wheelset by Grether et al. [149]. The information of the leading bogie is used for an advanced control of the trailing one, leading to a further improvement in terms of wear number.

Using the lateral displacement and the yaw angle of the IRW wheelset as feedback, Lu et al. [142] developed a robust torque control using $\mu$-synthesis. To reduce the complexity of the model, the control is based only on the model of the IRW wheelset using the bogie force and torque as external inputs. The simulation results are then experimentally validated on a 1:5 scaled test rig.

A comparison of the control performances between ASW, SYC and DRIW controlled with zero lateral clearance was proposed by Farhat et al. in [98]. Simulations are performed showing that for the cases studied DIRW performs better than other solutions. In particular, SYC is the least advantageous method. Nevertheless, Farhat et al. [143] showed that degraded performances can be seen in the diverging route of switches with respect to standard solid wheelsets, especially for high-speed switches. This does not apply to the through route though.

\section{b.4 Differential traction control}

By a combination of AIRW and DIRW concepts, Pérez et al. [137] provided steering with the AIRW concept and guidance with the DIRW concept. To facilitate the task of the steering procedure of the AIRW part, the torque on the two wheels is controlled to be equal with the DIRW part. In this way, the contact forces on the left and right wheel are virtually kept equal. In [137], the dynamic model of the synchronous motor was introduced. The separation method of field and armature winding equations is used, and the control is designed considering the field current constant.

\section{b.5 DSW}

On DSW, a first approach for guidance was proposed by Wickens in [150] where the wheels are steered by an angle proportional to the tracking error. The tracking error is here defined as the error of the vehicle position with respect to the track centreline. Subsequently, a passive bogie with self-steering capability was introduced by Michitsuji and Suda in [153]. Here, a feedforward action is introduced to improve the vehicle behaviour during curve transition by compensating the disturbances that emerge from the time variation of the track curvature. The effectiveness of the solution is shown by simulation results and experimental ones carried out on a 1:10 scaled test rig.

Table 5 compares the features of different guidance controls.

\subsubsection{Implementation}

Controlled independently rotating wheels are an interesting concept, having potential advantages over actively controlled solid wheelsets. Nevertheless, known implementations consist of scaled models, with exception described in [157].

The first application of a DIRW concept was developed by DLR in 1999 by Gretzschel and Bose [128] and was further developed in [138]. In the 1:5 scaled test rig of Fig. 32, the differential control is provided by an external servomotor mounted directly between the two wheels through a gearbox. The applied scaling procedure together with the obtained results is given in [158].

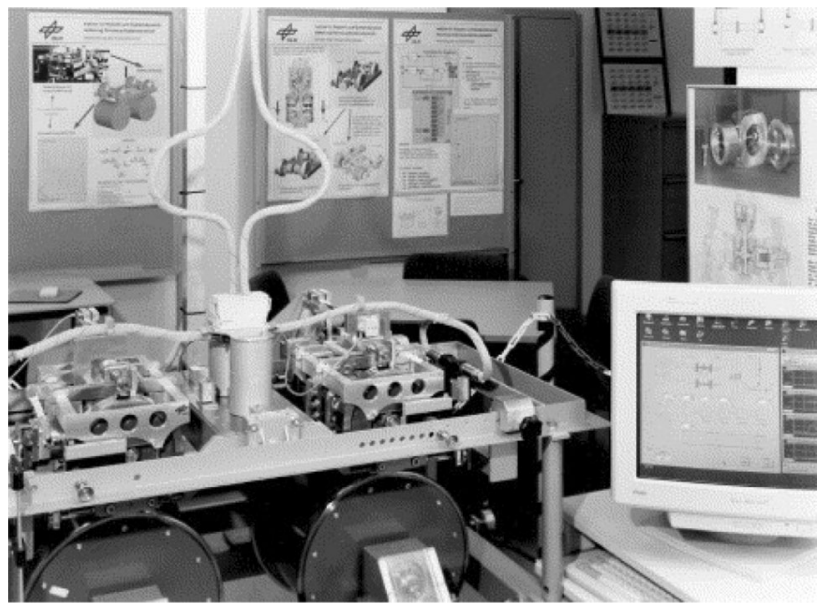

Fig. 32 First 1:5 scaled test rig for DIRW [138] 


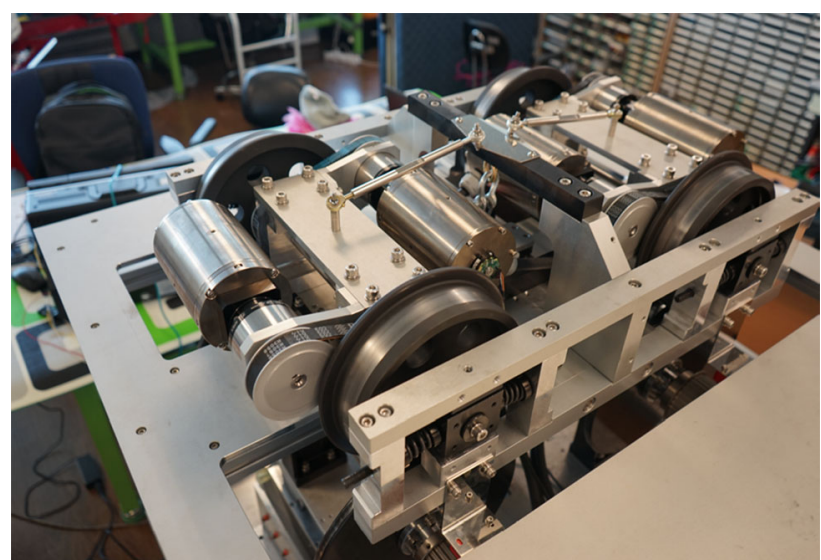

Fig. 33 A 1:5 scaled test rig for high-depth subway system [141]

A 1:5 scaled wheelset was developed and tested by Liang et al. [139], [140]. Both DC and AC motors were considered. Only AC motors were tested. Equal wheel speeds and absolute yaw velocity feedback controls were applied. Good agreement of results between simulations and experiments are found. Additionally, the behaviour of the test wheelset with and without absolute yaw velocity feedback control are reported to show significant improvements when the control is applied. Another 1:5 scaled test rig was implemented by Ahn et al. [141] representing a high-depth subway system where a linear scaling was applied. Surface permanent magnet synchronous motors are used, and zero lateral clearance strategy is applied with the usage of a saturated PI controller. In Fig. 33, the above-mentioned test rig is shown.

A robust control approach was successfully applied on a 1:5 test rig by Lu et al. [142]. The scaled vehicle runs on a real track with reduced gauge differently from most of the applications that involve tests on experimental IRW

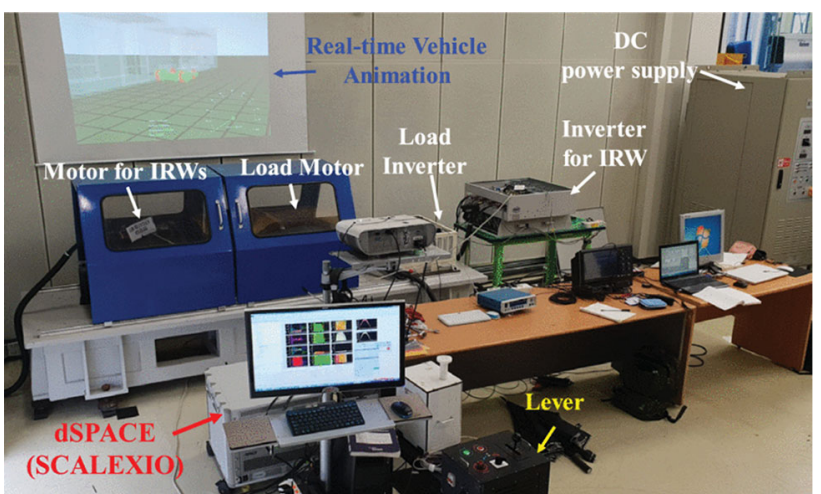

Fig. 35 Hardware-in-the-loop test configuration [159]

vehicles. A zero lateral clearance control is applied where eddy current displacement sensors are used on both left and right wheels. The two signals are then used to estimate the wheel-rail lateral displacement and the yaw angle. In Fig. 34, the experimental vehicle is shown.

A different approach was chosen by Oh et al. [159]. Instead of developing a scaled model of the vehicle, a hardware-in-the-loop (HIL) approach is used to study the real-time behaviour of a full-scale wheel motor. A linear vehicle model is used to simulate the vehicle behaviour in which the longitudinal dynamics is considered too. Simulations and wheel motor are coupled by a load motor. The use of a linear model is justified by the need to run the model in real-time, while a more complex, nonlinear model might cause time lag in the computation of the vehicle dynamics, eventually hindering the implementation HIL. The vehicle is controlled using the zero lateral clearance strategy. The experimental set-up is shown in Fig. 35. The


Fig. 34 A 1:5 scaled vehicle on scaled track [142] 


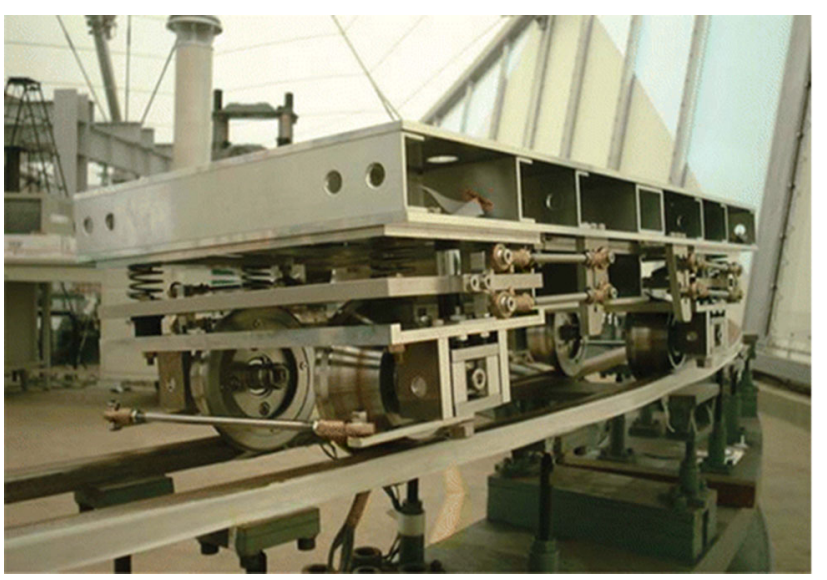

Fig. 36 EEF 1:10 scaled bogie test [153]

same authors designed the wheel motor armature windings to improve the motor performance $[160,161]$.

An application of DSW was proposed by Michitsuji et al. [153] on a 1:10 scaled model for the EEF bogie (Fig. 36). The vehicle was tested on a $25 \mathrm{~m}$ track with a curve of $3.3 \mathrm{~m}$ radius that corresponds to a very narrow curve of $33 \mathrm{~m}$ in real-scale track. The steering capability of the vehicle is improved with a feedforward control that assists the self-steering capability of the proposed design during transition curves. The vehicle is not actively steered during the circular part of the curve. A satisfactory agreement between simulation and experimental results is reported.

\section{Summary and outlook}

Active suspension for railway vehicles is defined as a technology with the inclusion of electronics like sensors, controllers and actuators. Over the past 40 years, it has developed into a comprehensive combination of various technologies which can substantially improve the dynamic behaviours of the vehicle in different aspects.

In this work, the basic concepts and classifications of active suspension are fully explained. For active primary suspension and secondary suspension, technologies are carefully summarized from perspectives of working principle, mechanical configurations, control strategies and implementation status. Over the last decade, many classic concepts have evolved much new progress from theory to implementation but, apart from tilting trains, widespread adoption of active suspension technology into service operation has not taken place. A general overview of different active suspension concepts is summarized in Table 6 in terms of targets, benefits, maturity/research status, current research attention, challenges and relevant sections in this paper. Both benefits and research attention are graded from 'low' to 'very high'. The level of maturity/ research status is represented by stars, where one star means that only simulations results are performed so far while five stars mean developed technology.

The authors believe that extensive application of active suspension technologies is only a matter of time, but there are key issues for the future which will help to liberate their wider use.

Firstly, industry-based cost-benefit analyses are essential to fully identify the prospective impact in an emphatic manner. Until now, business cases have been found in high performance trains, where the additional cost of the active system is small in relation to the overall cost. Nevertheless, as shown in Table 6, the benefits that may derive from the application of active systems are meaningful. Considering the large maintenance cost on train and infrastructure arising from the wear and RCF on wheel and rail, the future best business case may be a train with active primary suspension, which is expected to produce more benefits than active secondary suspensions. Among active primary suspensions, ASW may be one of the most promising technologies in the near future due to its potential high benefits in terms of wear and its relatively simple implementation. A further significant improvement would be achieved by controlled independently rotating wheels, for which a field test has been performed recently.

Also, fault tolerance design and analysis, especially for the actuation systems, is very important because safe operation is an aspect which the industry is most concerned about. The development of affordable safe and reliable solutions which yield excellent maintainability and availability solutions is therefore critical. This is a topic deserving more research work in the future, also taking benefit from examples and best practices from other technology fields, aircraft industry in particular, to ensure the safety and improve the reliability of railway vehicles with mechatronic suspensions, for instance adopting backups or redundant structures.

The future may lie in downsizing the actuator, which gives less resistance to relative motion and thereby less risk for vibrational transfer. A typical application of a downsized actuator may be in the secondary suspension aiming to improve the vibrational ride comfort. This means that quasi-static forces must be handled by the passive system and the passive suspension be made stiffer if less displacements are requested. The active system will in this case compensate for the increased force transfer the stiffer passive suspension brings.

The academic world has for a long time tried to find control algorithms that provide better performances. A recent trend is that the performances are set in relation to 


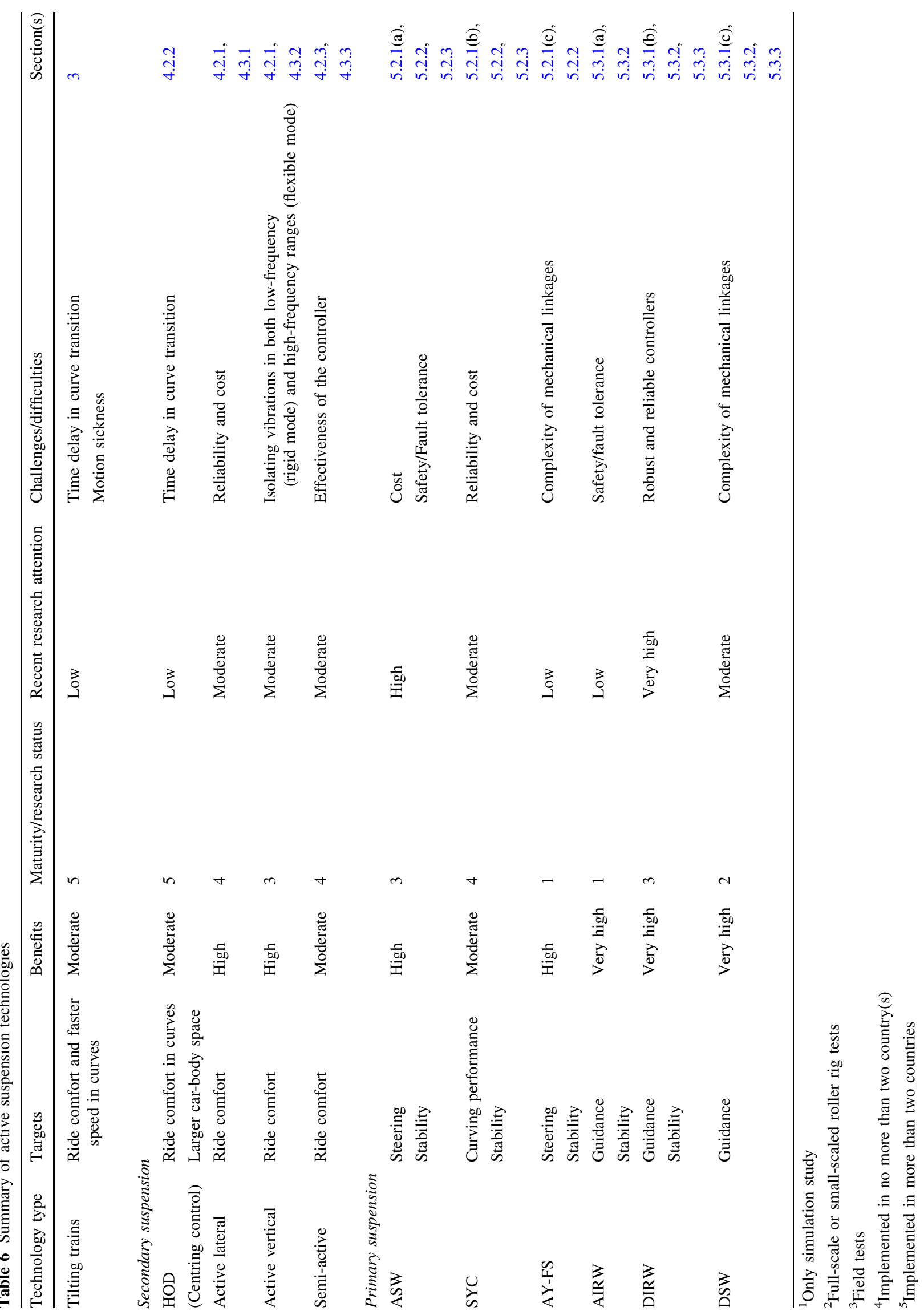


the complexity and that fewer sensors and sensors less likely to fail are used. Moreover, experimental studies are increasing for both active primary and secondary suspensions actuation systems. The more historically developed active secondary suspension technology tends to result in a higher possibility of field tests. Nevertheless, some active primary suspensions field tests have been carried out, showing promising results.

Recently, the work done in the Run2Rail project, for which this state-of-the-art survey has been undertaken, makes important contributions. In particular, it has included the following aspects: new lightweight architectures for vehicles made possible by mechatronic suspensions; assessment of semi-active secondary and primary suspensions to improve ride comfort and running gear performance; the design and optimization of fault-tolerant configurations; an authorization framework for a vehicle with mechatronic suspensions; potential impact assessments. Several of the above-mentioned aspects will be followed up in the recently started Shift2Rail projects NEXTGEAR and PIVOT-2. Studies will be extended to higher TRL-levels to be able to propose concepts that clearly demonstrate the potential benefits of active suspension technology.

Acknowledgements Funding was provided by Horizon 2020 Framework Programme (Grant No. 777564).

Open Access This article is licensed under a Creative Commons Attribution 4.0 International License, which permits use, sharing, adaptation, distribution and reproduction in any medium or format, as long as you give appropriate credit to the original author(s) and the source, provide a link to the Creative Commons licence, and indicate if changes were made. The images or other third party material in this article are included in the article's Creative Commons licence, unless indicated otherwise in a credit line to the material. If material is not included in the article's Creative Commons licence and your intended use is not permitted by statutory regulation or exceeds the permitted use, you will need to obtain permission directly from the copyright holder. To view a copy of this licence, visit http://creativecommons. org/licenses/by/4.0/.

\section{References}

1. Goodall RM, Kortüm W (1983) Active controls in ground transportation-review of the state-of-the-art and future potential. Veh Syst Dyn 12(4-5):225-257

2. Goodall RM (1997) Active railway suspensions: implementation status and technological trends. Veh Syst Dyn 28:87-117

3. Mei TX, Goodall RM (2003) Recent development in active steering of railway vehicles. Veh Syst Dyn 39(6):415-436

4. Bruni S, Goodall R, Mei TX, Tsunashima H (2007) Control and monitoring for railway vehicle dynamics. Veh Syst Dyn 45(7-8):743-779

5. Persson R, Goodall RM, Sasaki K (2009) Carbody tiltingtechnologies and benefits. Veh Syst Dyn 47(8):949-981
6. Anubi OM, Patel DR, Crane CD (2013) A new variable stiffness suspension system: passive case. Mech Sci 4(1):139-151

7. Hu Y, Chen MZQ, Xu S, Liu Y (2017) Semiactive inerter and its application in adaptive tuned vibration absorbers. IEEE Trans Control Syst Technol 25(1):294-300

8. Mei TX, Zaeim A, Li H (2020) Control of railway wheelsets - a semi-active approach. In: Klomp M, Bruzelius F, Nielsen J, Hillemyr A (eds) Advances in dynamics of vehicles on roads and tracks. IAVSD 2019. Lecture Notes in mechanical engineering. Springer, Cham

9. Van Dorn W, Beemer P (1938) Suspension for vehicles. US Patent

10. Anon. "Tilting Train". http://en.wikipedia.org/wiki/Tilting. Accessed 2019

11. Anon. "Talgo". https://en.wikipedia.org/wiki/Talgo. Accessed 2019

12. Kitada H (2017) History of air spring development for Shinkansen trains. SEI Tech Rev 84:114-119

13. Talgo. "Talgo XXI". http://www.talgo.es/pdf/T21ingles.pdf. Accessed 2019

14. Zamzuri H, Zolotas AC, Goodall RM (2006) Intelligent control approaches for tilting railway vehicles. Veh Syst Dyn 44(sup1):834-842

15. Hassan F, Zolotas AC, Smith T (2017) Optimized Ziegler-Nichols based PID control design for tilt suspensions. J Eng Sci Technol Rev 10(5):17-24

16. Hassan F, Zolotas AC, Margetts RM (2017) Optimised PID control for tilting trains. Syst Sci Control Eng 5(1):25-41

17. Zhou R, Zolotas A, Goodall R (2011) Integrated tilt with active lateral secondary suspension control for high speed railway vehicles. Mechatronics 21(6):1108-1122

18. Zhou R, Zolotas A, Goodall R (2014) Robust system state estimation for active suspension control in high-speed tilting trains. Veh Syst Dyn 52(sup1):355-369

19. Facchinetti A, Di Gialleonardo E, Resta F, Bruni S, Brundisch V (2011) Active control of secondary airspring suspension. In: Proceedings of the 22nd international symposium dynamics of vehicles on roads tracks (IAVSD 2011), pp 1-7

20. Alfi S, Bruni S, Diana G, Facchinetti A, Mazzola L (2011) Active control of airspring secondary suspension to improve ride quality and safety against crosswinds. Proc Inst Mech Eng Part F J Rail Rapid Transit 225(1):84-98

21. Colombo EF, Di Gialleonardo E, Facchinetti A, Bruni S (2014) Active carbody roll control in railway vehicles using hydraulic actuation. Control Eng Pract 31:24-34

22. Jacazio G, Risso D, Sorli M, Tomassini L (2012) Adaptive control for improved efficiency of hydraulic systems for highspeed tilting trains. Proc Inst Mech Eng Part F J Rail Rapid Transit 226(3):272-283

23. Hauser G (2006) Alstom's Tiltronix anticipative tilt control. Le Rail 129:6-7

24. Persson R, Kufver B, Berg M (2012) On-track test of tilt control strategies for less motion sickness on tilting trains. Veh Syst Dyn 50(7):1103-1120

25. Mei TX, Goodall RM (2002) Use of multiobjective genetic algorithms to optimize inter-vehicle active suspensions. Proc Inst Mech Eng Part F J Rail Rapid Transit 216(1):53-63

26. Zhou J, Ren L, Shen G, Zhong T (2004) Inter-vehicle active suspension control strategies to improve lateral riding quality in high-speed railway trains. J China Railw Soc 26(6):31-35

27. Sugahara Y, Kojima T (2018) Suppression of vertical vibration in railway vehicle carbodies through control of damping force in primary suspension: presentation of results from running tests with meter-gauge car on a secondary line. WIT Trans Built Environ 181:329-337 
28. CEN; EN12299 (2009) Railway applications—ride comfort for passengers-measurement and evaluation. British Standard, Brussels

29. Method for Assessing Raiding Quality of Vehicle (April 1977), Report C116/RP 8, Office for Research and Experiments, Utrecht, Netherlands

30. Orvnäs A (2010) Methods for reducing vertical carbody vibrations of a rail vehicle: a literature survey

31. Orvnas A, Stichel S, Persson R (2011) Active lateral secondary suspension with $\mathrm{H} \infty$ control to improve ride comfort: simulations on a full-scale model. Veh Syst Dyn 49(9):1409-1422

32. Orvnäs A, Stichel S, Persson R (2011) Aspects of using active vertical secondary suspension to improve ride comfort. In: Proceedings of the 22nd international symposium on dynamics of vehicle on roads and tracks (IAVSD 2011), pp 1-6

33. Hammood H, Mei TX (2017) Gain-sheduling control for railway vehicle semi-active suspension. In: Proceedings of the 25th international symposium on dynamics of vehicle on roads and tracks (IAVSD 2017), pp 893-899

34. Sugahara Y, Kojima T, Akami Y, Igarashi Y (2016) Development of a vertical semi-active suspension system using variable hydraulic dampers. In: Proceedings of the 15th international conference on railway engineering design and operation (CR 2016)

35. Yusof MdH, Goodall R, Dixon R (2011) Controller strategies for active secondary suspension actuators. In: Proceedings of the 22nd international symposium on dynamics of vehicle on roads and tracks (IAVSD 2011)

36. Qazizadeh A, Persson R, Stichel S (2015) Preparation and execution of on-track tests with active vertical secondary suspension. Int J Railw Technol 4(1):29-46

37. Qazizadeh A, Persson R, Stichel S (2015) On-track tests of active vertical suspension on a passenger train. Veh Syst Dyn 53(6):798-811

38. Karnopp D (1995) Active and semi-active vibration isolation. ASME J Vib Acoust 117(B):177-185

39. Sugahara Y, Kazato A, Takigami T, Koganei R (2008) Suppression of vertical vibration in railway vehicles by controlling the damping force of primary and secondary suspensions. Q Rep RTRI 49(1):7-15

40. Sugahara Y, Takigami T, Koganei R (2009) Suppression of vertical bending vibration in railway car bodies by primary suspension damping control (results of running tests using shinkansen vehicles). In: Proceedings of the 21st international symposium on dynamics of vehicle on roads and tracks (IAVSD 2009), pp 1-12

41. Gopala Rao LVV, Narayanan S (2009) Sky-hook control of nonlinear quarter car model traversing rough road matching performance of LQR control. J Sound Vib 323(3-5):515-529

42. Pacchioni A, Goodall RM, Bruni S (2010) Active suspension for a two-axle railway vehicle. Veh Syst Dyn 48(sup1):105-120

43. Orukpe PE, Zheng X, Jaimoukha IM, Zolotas AC, Goodall RM (2008) Model predictive control based on mixed $\mathscr{H} 2 / \mathscr{H} \infty$ control approach for active vibration control of railway vehicles. Veh Syst Dyn 46(sup1):151-160

44. Li H, Goodall RM (1999) Linear and non-linear skyhook damping control laws for active railway suspensions. Control Eng Pract 7:843-850

45. Turnip A, Hong K-S, Park S (2008) Control of a semi-active MR-damper suspension system: a new polynomial model. IFAC Proc 41(2):4683-4688

46. Gong D, Zhou J, Sun W, Goodall R (2011) Effects of active primary suspension on vertical ride quality control of flexible car body and its comparison with those of active secondary suspension. In: Proceedings of the 22nd international symposium on dynamics of vehicles on roads tracks (IAVSD 2011), vol 1, no 1, pp 1-6

47. Leblebici AS, Türkay S (2016) Track modelling and control of a railway vehicle. IFAC-PapersOnLine 49(21):274-281

48. Nagarkar M, Bhalerao Y, Patil GV, Patil RZ (2018) Multi-objective optimization of nonlinear quarter car suspension system-PID and LQR control. Procedia Manuf 20:420-427

49. Hirata T, Takahashi R (1993) H_inf control of railroad vehicle active suspension. In: Proceedings of the 32nd conference on decision and control, pp 2937-2942

50. Hirata T, Koizumi S, Takahashi R (1995) Hळ control of railroad vehicle active suspension. Automatica 31(1):13-24

51. Kamada T, Hiraizumi K, Nagai M (2010) Active vibration suppression of lightweight railway vehicle body by combined use of piezoelectric actuators and linear actuators. Veh Syst Dyn 48(sup1):73-87

52. Kamada T, Mikazuki T, Nagai M (2011) Active vibration suppression of railway vehicle by air actuators. In: Proceedings of the 22nd international symposium on dynamics of vehicle on roads and tracks (IAVSD 2011), pp 1-6

53. Kamada T, Makino T (2013) Active vertical elastic vibration suppression of railway vehicle by air spring suspension. In: Proceedings of the 23rd international symposium on dynamics of vehicle on roads and tracks (IAVSD 2013), pp 1-7

54. Leblebici AS, Türkay S (2018) An H $\infty$ and skyhook controller design for a high speed railway vehicle. IFAC-PapersOnLine 51(9):156-161

55. Zadeh LA (1965) Fuzzy sets. Inf Control 8:338-353

56. Guclu R, Metin M (2009) Fuzzy logic control of vibrations of a light rail transport vehicle in use in Istanbul traffic. JVC/J Vib Control 15(9):1423-1440

57. Metin M, Guclu R (2011) Active vibration control with comparative algorithms of half rail vehicle model under various track irregularities. JVC/J Vib Control 17(10):1525-1539

58. Sezer S, Atalay AE (2012) Application of fuzzy logic based control algorithms on a railway vehicle considering random track irregularities. JVC/JVib Control 18(8):1177-1198

59. Goodall RM, Mei TX (2006) Handbook of railway vehicle dynamics. In: Iwnicki S (ed) Handbook of railway vehicle dynamics. CRC Press, Boca Raton, pp 327-357

60. Allen DH (1994) Active bumpstop hold-off device. In: Proc IMechE conference Railtech 94, p. paper C478/5/013

61. Vinolas J, Alonso A, Nieto J, Giménez JG (2019) The design of a hold-off device to improve the lateral comfort of rail vehicles. Veh Syst Dyn 57(11):1666-1684

62. Zong L-H, Gong X-L, Xuan S-H, Guo C-Y (2013) Semi-active $\mathrm{H} \infty$ control of high-speed railway vehicle suspension with magnetorheological dampers. Veh Syst Dyn 51(5):600-626

63. Savaresi SM, Silani E, Bittanti S (2005) Acceleration-drivendamper (ADD): an optimal control algorithm for comfort-oriented semiactive suspensions. J Dyn Syst Meas Control 127(2): 218

64. Savaresi SM, Spelta C (2007) Mixed sky-hook and ADD: approaching the filtering limits of a semi-active suspension. J Dyn Syst Meas Control 129(4):382

65. Hudha K, Harun MH, Harun MH, Jamaluddin H (2011) Lateral suspension control of railway vehicle using semi-active magnetorheological damper. In: 2011 IEEE intelligent vehicles symposium (IV), No. IV, pp 728-733

66. Wang DH, Liao WH (2009) Semi-active suspension systems for railway vehicles using magnetorheological dampers. Part I: system integration and modelling. Veh Syst Dyn 47(11):1305-1325

67. Wang DH, Liao WH (2009) Semi-active suspension systems for railway vehicles using magnetorheological dampers. Part II: simulation and analysis. Veh Syst Dyn 47(12):1439-1471 
68. Sugahara Y, Takigami T, Kazato A, Koganie R, Sampei M (2008) Suppression of vertical vibration in railway vehicles by damping force control of primary suspension using an LQG controller. J Syst Des Dyn 2(1):251-262

69. Goodall RM, Williams RA, Lawton A, Harborough PR (1981) Railway vehicle active suspensions in theory and practice. Veh Syst Dyn 10(2-3):210-215

70. Stribersky A, Steidl S, Müller H, Rath B (1996) On dynamic analyses of rail vehicles with electronically controlled suspensions. VehSyst Dyn 25(sup1):614-628

71. Stribersky A, Müller H, Rath B (1998) The development of an integrated suspension control technology for passenger trains. Proc Inst Mech Eng Part F J Rail Rapid Transit 212(1):33-42

72. Stribersky A, Kienberger A, Wagner G, Müller H (2007) Design and evaluation of a semi-active damping system for rail vehicles. Veh Syst Dyn 29(1):669-681

73. Trafikverket. "Gröna Tåget. http://www.gronataget.se. Accessed 2019

74. Orvnäs A, Stichel S, Persson R (2010) Ride comfort improvements in a high-speed train with active secondary suspension. J Mech Syst Transp Logist 3(1):206-215

75. Park J, Shin Y, Hur H, You W (2019) A practical approach to active lateral suspension for railway vehicles. Meas Control 52(9-10):1195-1209

76. Tanifuji K, Koizumi S, Shimamune RH (2002) Mechatronics in Japanese rail vehicles: active and semi-active suspensions. Control Eng Pract 10(9):999-1004

77. Maruyama Y, Ishihara K, Matsui T, Koizumi S (1997) Development of an active suspension systems for railway vehicles. Sumitomo Search 59:108-112

78. Sasaki K, Kamoshita S, Enomoto M (2002) A design and bench test of multi-modal active suspension of railway vehicle. In: Proceedings of IECON'94-20th annual conference of IEEE industrial electronics, vol 3, pp 2011-2016

79. Orvnäs A (2008) Active secondary suspension in trains: a literature survey of concepts and previous work. KTH, Stockholm

80. Asano K (2015) JR east high-speed rolling stock development. JR East Tech Rev 36:1-6

81. Goto O (2013) Development of active suspension system with electromechanical actuators for railway vehicles

82. O'Neill HR, Wale GD (2005) Semi-active suspension improves rail vehicle ride. Comput Control Eng J 5(4):183-188

83. Roth P-A, Lizell M (1996) A lateral semi-active damping system for trains. Veh Syst Dyn 25(sup1):585-598

84. Shin YJ, You WH, Hur HM, Park JH (2012) Semi-active control to reduce carbody vibration of railway vehicle by using scaled roller rig. J Mech Sci Technol 26(11):3423-3431

85. Shin YJ, You WH, Hur HM, Park JH (2014) Hळo control of railway vehicle suspension with MR damper using scaled roller rig. Smart Mater Struct 23(9):095023

86. Shin Y-J, You W-H, Hur H-M, Park J-H, Lee G-S (2014) Improvement of ride quality of railway vehicle by semiactive secondary suspension system on roller rig using magnetorheological damper. Adv Mech Eng 6:1-10

87. Kwak MK, Lee JH, Yang DH, You WH (2014) Hardware-inthe-loop simulation experiment for semi-active vibration control of lateral vibrations of railway vehicle by magneto-rheological fluid damper. Veh Syst Dyn 52(7):891-908

88. Kim HC, Shin YJ, You W, Jung KC, Oh JS, Choi SB (2017) A ride quality evaluation of a semi-active railway vehicle suspension system with MR damper: railway field tests. Proc Inst Mech Eng Part F J Rail Rapid Transit 231(3):306-316

89. Sugahara Y, Kazato A, Koganei R, Sampei M, Nakaura S (2009) Suppression of vertical bending and rigid-body-mode vibration in railway vehicle car body by primary and secondary suspension control: results of simulations and running tests using
Shinkansen vehicle. Proc Inst Mech Eng Part F J Rail Rapid Transit 223(6):517-531

90. Polach O (2004) Curving and stability optimisation of locomotive bogies using interconnected wheelsets. Veh Syst Dyn 41(SUPPL):53-62

91. Perez J, Stow JM, Iwnicki SD (2006) Application of active steering systems for the reduction of rolling contact fatigue on rails. Veh Syst Dyn 44(sup1):730-740

92. Mei TX, Goodall RM (1999) Wheelset control strategies for a two-axle railway vehicle. Veh Syst Dyn 33(sup1):653-664

93. Park J-H, Koh H-I, Hur H-M, Kim M-S, You W-H (2010) Design and analysis of an active steering bogie for urban trains. J Mech Sci Technol 24(6):1353-1362

94. Umehara Y, Kamoshita S, Ishiguri K, Yamanaga Y (2014) Development of electro-hydraulic actuator with fail-safe function for steering system. Q Rep RTRI 55(3):131-137

95. Fu B, Bruni S (2020) Fault-tolerant analysis for active steering actuation system applied on conventional Bogie vehicle. In: Klomp M, Bruzelius F, Nielsen J, Hillemyr A (eds) Advances in dynamics of vehicles on roads and tracks. IAVSD 2019. Lecture notes in mechanical engineering. Springer, Cham

96. Shen G, Goodall R (1997) Active yaw relaxation for improved bogie performance. Veh Syst Dyn 28:273-289

97. Hwang IK, Hur HM, Kim MJ, Park TW (2018) Analysis of the active control of steering bogies for the dynamic characteristics on real track conditions. Proc Inst Mech Eng Part F J Rail Rapid Transit 232(3):722-733

98. Farhat N, Ward CP, Goodall RM, Dixon R (2018) The benefits of mechatronically-guided railway vehicles: a multi-body physics simulation study. Mechatronics 51(March):115-126

99. Diana G, Bruni S, Cheli F, Resta F (2002) Active control of the running behaviour of a railway vehicle: stability and curving performances. Veh Syst Dyn 37(sup1):157-170

100. Braghin F, Bruni S, Resta F (2006) Active yaw damper for the improvement of railway vehicle stability and curving performances: simulations and experimental results. Veh Syst Dyn 44(11):857-869

101. Yao Y, Wu G, Sardahi Y, Sun J-Q (2018) Hunting stability analysis of high-speed train bogie under the frame lateral vibration active control. Veh Syst Dyn 56(2):297-318

102. Yue H, Yadong S, Guosong W, Yun L, Yuan Y (2019) Simulation and experimental study on the active stability of highspeed trains. Comput Sci Eng 21(3):72-82

103. Simson SA, Cole C (2007) Idealized steering for hauling locomotives. Proc Inst Mech Eng Part F J Rail Rapid Transit 221(2):227-236

104. Simson SA, Cole C (2009) Simulation of traction curving for active yaw-force steered bogies in locomotives. Proc Inst Mech Eng Part F J Rail Rapid Transit 223(1):75-84

105. Simson SA, Cole C (2011) Simulation of active steering control for curving under traction in hauling locomotives. Veh Syst Dyn 49(3):481-500

106. Carballeira J, Baeza L, Rovira A, García E (2008) Technical characteristics and dynamic modelling of Talgo trains. Veh Syst Dyn 46(sup1):301-316

107. Hur H, Shin Y, Ahn D, Ham Y (2019) Steering performance evaluation of active steering bogie to reduce wheel wear on test line. Int J Precis Eng Manuf 20(9):1591-1600

108. Pérez J, Busturia JM, Goodall RM (2002) Control strategies for active steering of bogie-based railway vehicles. Control Eng Pract 10(9):1005-1012

109. Shen S, Mei TX, Goodall RM, Pearson J, Himmelstein G (2004) A study of active steering strategies for railway bogie. Veh Syst Dyn 41(suppl):282-291

110. Giossi RL, Persson R, Stichel S (2020) Gain scaling for active wheelset steering on innovative two-axle vehicle. In: Klomp M, 
Bruzelius F, Nielsen J, Hillemyr A (eds) Advances in dynamics of vehicles on roads and tracks. IAVSD 2019. Lecture notes in mechanical engineering. Springer, Cham

111. Ward CP, Goodall RM, Dixon R, Charles GA (2012) Adhesion estimation at the wheel-rail interface using advanced modelbased filtering. Veh Syst Dyn 50(12):1797-1816

112. Pearson JT et al (2004) Design and experimental implementation of an active stability system for a high-speed bogie. Veh Syst Dyn 41(suppl):43-52

113. Mei TX, Goodall RM (2006) Stability control of railway bogies using absolute stiffness: sky-hook spring approach. Veh Syst Dyn 44(sup1):83-92

114. Mousavi Bideleh SM, Mei TX, Berbyuk V (2016) Robust control and actuator dynamics compensation for railway vehicles. Veh Syst Dyn 54(12):1762-1784

115. Qazizadeh A, Stichel S, Feyzmahdavian HR (2018) Wheelset curving guidance using Hळocontrol. Veh Syst Dyn 56(3):461-484

116. Matsumoto A et al (2004) Research on high curving performance trucks - concept and basic characteristics of active-bogiesteering truck. Veh Syst Dyn 41(suppl):33-42

117. Michálek T, Zelenka J (2011) Reduction of lateral forces between the railway vehicle and the track in small-radius curves by means of active elements. Appl Comput Mech 5(2):187-196

118. Ishiguri K, Shimoda K, Yamanaga $\mathrm{Y}$, Kamoshita S, Ishige M (2011) Analysis of failsafe hydraulic actuation system using passive relief valves; application for power assisting devices. In: Proceedings of the 8th JFPS international symposium of fluid power, pp 413-418

119. Hur H, Ahn D, Shin Y (2018) Steering performance evaluation of active steering system for a railway vehicle by simulating real track running. Int J Precis Eng Manuf 19(10):1487-1494

120. CRRC. CETROVO carbon-fibre metro vehicles. https://railwaynews.com/crrc-global-release-cetrovo-carbon-fibre-metrovehicles/. Accessed 2019

121. Bombardier. TWINDEXX double-deck trains. https://www. railway-technology.com/projects/bombardier-twindexx-doubledeck-trains/. Accessed 2019

122. Goodall R, Mei TX (2001) Mechatronic strategies for controlling railway wheelsets with independently rotating wheels. In: 2001 IEEE/ASME international conference on advanced intelligent mechatronics. Proceedings (Cat. No.01TH8556), vol 1, no. July, pp 225-230

123. Perez J, Mauer L, Busturia JM (2002) Design of active steering systems for bogie-based railway vehicles with independently rotating wheels. Veh Syst Dyn 37(sup1):209-220

124. Kurzeck B, Valente L (2011) A novel mechatronic running gear: concept, simulation and scaled roller rig testing. In: 9th world congress railway research, pp 1-10

125. Meyer A (2016) Wheel sets or independently rotating wheelsfrom theory to practice. Siemens AG, pp 1-12

126. Cho Y, Kwak J (2012) Development of a new analytical model for a railway vehicle equipped with independently rotating wheels. Int J Automot Technol 13(7):1047-1056

127. Sugiyama H, Matsumura R, Suda Y, Ezaki H (1882) Analysis of independently rotating wheel system using multibody dynamics approach. In: Volume 4: 7th international conference on multibody systems, nonlinear dynamics, and control, parts A, B and C, pp 1875-1882

128. Gretzschel M, Bose L (1999) A mechatronic approach for active influence on railway vehicle running behaviour. Veh Syst Dyn 33(Supplement):418-430

129. Goodall RM, Bruni S, Facchinetti A (2012) Active control in railway vehicles. Int J Railw Technol 1(1):57-85
130. Aknin P, Ayasse JB, Devallez A (1992) Active steering of railway wheelsets. In: Proceedings of the 12th IAVSD conference

131. Wu X, Chi M, Zeng J, Zhang W, Zhu M (2014) Analysis of steering performance of differential coupling wheelset. J Mod Transp 22(2):65-75

132. Bracciali A, Megna G (2016) Contact mechanics issues of a vehicle equipped with partially independently rotating wheelsets. Wear 366-367:233-240

133. Suda Y (2008) The possibility of a new concept of self-steering truck with independently rotating wheels. J-RAIL 2008, pp 473-476

134. Mei TX, Goodall RM (2001) Robust control for independently rotating wheelsets on a railway vehicle using practical sensors. IEEE Trans Control Syst Technol 9(4):599-607

135. Mei TX, Goodall RM (2003) Practical strategies for controlling railway wheelsets independently rotating wheels. J Dyn Syst Meas Control 125(3):354

136. Mei TX, Lu JW (2004) On the interaction and integration of wheelset control and traction system. Veh Syst Dyn 41(Supplement): 123-132

137. Pérez J, Busturia JM, Mei TX, Vinolas J (2004) Combined active steering and traction for mechatronic bogie vehicles with independently rotating wheels. Annu Rev Control 28(2):207-217

138. Gretzschel M, Bose L (2002) A new concept for integrated guidance and drive of railway running gears. Control Eng Pract 10(9):1013-1021

139. Liang B, Iwnicki SD (2007) An experimental study of independently rotating wheels for railway vehicles. In: 2007 International conference on mechatronics and automation, pp 2282-2286

140. Liang B, Iwnicki SD (2011) Independently rotating wheels with induction motors for high-speed trains. J Control Sci Eng 2011:1-7

141. Ahn H, Lee H, Go S, Cho Y, Lee J (2016) Control of the lateral displacement restoring force of IRWs for sharp curved driving. J Electr Eng Technol 11(4):1044-1050

142. Lu Z-G, Yang Z, Huang Q, Wang X-C (2019) Robust active guidance control using the $\mu$-synthesis method for a tramcar with independently rotating wheelsets. Proc Inst Mech Eng Part F J Rail Rapid Transit 233(1):33-48

143. Farhat N, Ward CP, Dixon R, Goodall RM (2018) Benefits of mechatronically guided vehicles on railway track switches. Proc Inst Mech Eng Part F J Rail Rapid Transit 234:1-13

144. Mei TX, Li H, Goodall RM, Wickens AH (2002) Dynamics and control assessment of rail vehicles using permanent magnet wheel motors. Veh Syst Dyn 37(sup1):326-337

145. Ji Y, Ren L, Zhou J (2018) Boundary conditions of active steering control of independent rotating wheelset based on hub motor and wheel rotating speed difference feedback. Veh Syst Dyn 3114:1-16

146. Kurzeck B, Heckmann A, Wesseler C, Rapp M (2014) Mechatronic track guidance on disturbed track: the trade-off between actuator performance and wheel wear. Veh Syst Dyn 52(sup1):109-124

147. Grether G (2017) Dynamics of a running gear with IRWs on curved tracks for a robust control development. Pamm 17(1):797-798

148. Heckmann A, Daniel L, Grether G, Keck A (2017) From scaled experiments of mechatronic guidance to multibody simulations of DLR's next generation train set. In: Proceedings of the 25th international symposium on dynamics of vehicle on roads and tracks (IAVSD 2017)

149. Grether G, Heckmann A, Looye G (2020) Lateral guidance cntrol using information of preceding wheel pairs. In: Klomp M, 
Bruzelius F, Nielsen J, Hillemyr A (eds) Advances in dynamics of vehicles on roads and tracks. IAVSD 2019. Lecture notes in mechanical engineering. Springer, Cham

150. Wickens AH (1994) Dynamic stability of articulated and steered railway vehicles guided by lateral displacement feedback. Veh Syst Dyn 23(sup1):541-553

151. Wickens AH (2009) Comparative stability of bogie vehicles with passive and active guidance as influenced by friction and traction. Veh Syst Dyn 47(9):1137-1146

152. Powell A (1999) Mechatronic control of an actively guided rail vehicle. Veh Syst Dyn 33(sup1):442-452

153. Michitsuji Y, Suda Y (2006) Running performance of powersteering railway bogie with independently rotating wheels. Veh Syst Dyn 44(sup1):71-82

154. Michitsuji Y, Shiga R, Suda Y, Lin S, Makishima S (2017) Dynamics of vehicles on roads and tracks. In: Proceedings of the 25th international symposium on dynamics of vehicle on roads and tracks (IAVSD 2017), vol 2, pp 993-998

155. Michitsuji Y, Mizuno K, Suda Y, Lin S, Makishima S (2020) Curving performance evaluation of EEF bogie with inclined wheel axles using scale model vehicle. In: Klomp M, Bruzelius
F, Nielsen J, Hillemyr A (eds) Advances in dynamics of vehicles on roads and tracks. IAVSD 2019. Lecture Notes in Mechanical Engineering. Springer, Cham

156. Liu X, Goodall R, Iwnicki S (2020) A direct control approach for automatic steering and stability of motorized independentlyrotating wheels. In: Klomp M, Bruzelius F, Nielsen J, Hillemyr A (eds) Advances in Dynamics of Vehicles on Roads and Tracks. IAVSD 2019. Lecture Notes in Mechanical Engineering. Springer, Cham

157. Dobell M (2019) Steering a course. Rail Eng 180:28-30

158. Gretzschel M, Jaschinski A (2004) Design of an active wheelset on a scaled roller rig. Veh Syst Dyn 41(5):365-381

159. Oh YJ, Lee JK, Liu HC, Cho S, Lee J, Lee HJ (2019) Hardwarein-the-Loop Simulation for active control of tramcars with independently rotating wheels. IEEE Access 7:71252-71261

160. Oh YJ, Liu HC, Cho S, Won JH, Lee H, Lee J (2018) Design, modeling, and analysis of a railway traction motor with independently rotating wheelsets. IEEE Trans Magn 54(11):1-5

161. Liu HC, Lee HJ, Seol HS, Cho S, Lee J, Oh YJ (2019) Optimal slot design of IPMSM in railway with independently rotating wheelsets. IEEE Trans Magn 55(2):1-4 